\title{
Trabajos previos y paralelos integrados en el proyecto de restauración de la capilla de los Tocino (s. XV) en la iglesia de San Juan de los Caballeros de Jerez de la Frontera*
}

\author{
Integrated preliminary and parallel works in the restoration project for the \\ Chapel of Los Tocino (15th Century) in the Church of San Juan de los Caballeros \\ in Jerez de la Frontera
}

José María Guerrero Vega ${ }^{1}$, Francisco Pinto Puerto², Gregorio Mora Vicente ${ }^{3}$

Instituto Universitario de Arquitectura y Ciencias de la Construcción. Universidad de Sevilla

\begin{abstract}
RESUMEN
Consecuencia de una profunda reforma decimonónica inacabada, la capilla de los Tocino había perdido su uso y relación espacial original con el ábside de la iglesia de San Juan de los Caballeros de Jerez de la Frontera al que se adosa. La degradación que sufrió la capilla desde ese momento fue enorme. La interpretación de sus lesiones estaba muy condicionada por el devenir del mismo, siendo necesaria una serie de trabajos previos y paralelos a la intervención para reconocer esta complejidad y determinar los valores patrimoniales sobre los que fundamentar el proyecto. Se planteó así una estrategia de acciones de investigación cuyo alcance debía ser proporcional a los recursos económicos disponibles y los enfoques analíticos que pretendíamos integrar. Entre ellas se programó una intervención arqueológica que incorporaba el análisis del subsuelo y estudio paramental. Se expondrá el resultado de un trabajo integrado que se prolongó hasta finalizar su consolidación material, espacial y funcional.
\end{abstract}

Palabras clave: estrategia interdisciplinar; arqueología; proyecto integrado de restauración; gótico-mudéjar; marcas de cantería.

\begin{abstract}
Following a major but incomplete renovation in the 19th century, the Chapel of Los Tocino had lost its use and original spatial relationship with the apse to which it is abutted in the Church of San Juan de los Caballeros in Jerez de la Frontera. The degradation that the chapel suffered from that moment onwards was enormous. The interpretation of its pathologies was deeply conditioned by the fate of that building and it was therefore necessary to conduct a series of preliminary works parallel to the intervention in order to define this complexity and determine the heritage values that would underpin the project. We therefore established a strategy of research actions whose cost had to be proportionate to the funds available and the analytical approach we aimed to adopt. These actions included an archaeological intervention consisting in an analysis of the subsoil and the walls. Our paper will describe the results of an integrated project that concluded with the material, spatial and functional consolidation of the chapel.
\end{abstract}

Key words: interdisciplinary strategy; archeology; integrated restoration project; Gothic-Mudéjar; mason marks.

Recibido: 31-03-2018. Aceptado: 19-10-2018. Publicado online: 29-12-2019

Cómo citar este artículo / Citation

Guerrero Vega, J. M., Pinto Puerto, F. y Mora Vicente, G. 2019: "Trabajos previos y paralelos integrados en el proyecto de restauración de la capilla de los Tocino (s. XV) en la iglesia de San Juan de los Caballeros de Jerez de la Frontera", Arqueología de la Arquitectura, 16 : e086. https://doi.org/10.3989/arq.arqt.2019.008

Copyright: (C) CSIC, 2019. (C) UPV/EHU Press, 2019. Este es un artículo de acceso abierto distribuido bajo los términos de la licencia de uso y distribución Creative Commons Reconocimiento 4.0 Internacional (CC BY 4.0).

\footnotetext{
* El contenido de este artículo tiene como base los trabajos desarrollados en el marco de un contrato de investigación bajo el amparo de FIUS (Fundación para la Investigación de la Universidad de Sevilla) con referencia PRJ201402341, vinculado al proyecto de intervención arquitectónica.

1 jmgv@us.es / ORCID iD: https://orcid.org/0000-0003-3164-328X

fspp@us.es / ORCID iD: https://orcid.org/0000-0003-4608-6818

gmora@us.es / ORCID iD: https://orcid.org/0000-0003-2784-2438
} 


\section{INTRODUCCIÓN}

\subsection{Problemática y expectativas}

La presente aportación tiene como objeto describir el papel que la lectura estratigráfica y arqueológica tuvo en el proceso de intervención desarrollado en la capilla de los Tocino de la iglesia de San Juan de los Caballeros de Jerez de la Frontera, afectada por varios problemas estructurales, un importante grado de degradación y ciertas lagunas en el conocimiento sobre su devenir histórico ${ }^{4}$. Actuar sobre este edificio suponía enfrentarse a un objeto altamente vulnerable, al encontrarse muy alterado y abandonado tras una inacabada reforma comenzada a finales del siglo XIX. Gracias a este estado inconcluso el espacio de la capilla mantenía rastros de elementos originales inéditos, que podrían servir como indicadores cronológicos eficaces para reconocer su alterada estructura original. Por otro lado, la propia intervención decimonónica nos estaba informando de su modo de proceder, que de concluirse en ese momento histórico hubiera acabado transformando absolutamente la capilla. Pero ambas realidades han quedado superpuestas y presentes en el mismo espacio, confiriéndole una complejidad que no permitía reconocer ni su estado inicial, ni su final decimonónico. Por esta razón, el proyecto no podía atender solo a su consolidación estructural y a sus patologías, o la rehabilitación de aquel espacio para un nuevo uso. Era preciso poner un cierto orden en este proceso interrumpido, interpretar de forma adecuada cada una de las etapas que se acumulaban en sus fábricas. Para esto fue preciso desplegar un proceso que permitiera registrar cada uno de estos restos y valorar su papel en el devenir histórico de la capilla, convencidos de que, en conjunto, podían aportar las claves necesarias para su adecuada recuperación. La estrategia se centró en un proceso de trabajo conjunto de restauradores, arqueólogos, antropólogos, analistas de materiales y arquitectos, dirigido a la toma de decisiones más adecuadas a partir de los resultados obtenidos. Como consecuencia, el proyecto de intervención queda abierto a los datos que surgen de este proceso. Dos objetivos básicos se pretendían alcanzar con esta estrategia: recuperar la unidad espacial de la capilla, y poner en

\footnotetext{
${ }^{4}$ En el año 2014 se desarrollaron unos Trabajos de levantamiento, análisis y diagnóstico previos al proyecto de intervención, que finalizaron en enero de 2015. La intervención se desarrolló desde el 11 de mayo de 2015 hasta el 10 de octubre de 2016.
}

valor las singulares pinturas y elementos ornamentales pétreos conservados. Este tipo de elementos ha desaparecido en la mayoría de los edificios coetáneos del entorno, donde las intervenciones decimonónicas sí se concluyeron, por lo que la recuperación de este oratorio cobraba una mayor importancia.

\subsection{Localización y delimitación}

Según la tradición, el templo de San Juan se levantó en el lugar de una de las mezquitas de la ciudad islámica, que pasó a formar una de las parroquias intramuros de la ciudad cristiana $^{5}$. La capilla de los Tocino es parte de esta edificación, ocupando una superficie de suelo de $42 \mathrm{~m}^{2}$ sin contar el muro del presbiterio al que se adosa en su lado noroeste. De estos, $25 \mathrm{~m}^{2}$ son de espacio interior, quedando el resto ocupado por la masa de los muros que lo limitan. Linda al sur con la casa parroquial - actual casa de la hermandad de la Santa Cruz- - y por el norte con una pequeña nave de almacén - actualmente en peligro de desaparecer- . Por el oeste tiene fachada a la calle San Juan, y en el lado opuesto está adosada a la cabecera del templo.

Esta cabecera se constituye en lugar simbólico del edificio, donde aspiran a estar representadas las casas y familias principales de la época mediante símbolos y lápidas de enterramientos. Esta preeminencia determina la configuración de su estructura formal y constructiva como espacio abovedado donde se ponen en juego las novedades arquitectónicas del momento. Adosadas a este espacio, buscando su cercanía, se ubican la capilla de los Tocino y la de los Carrizosa, su simétrica. Su posición se entiende, por tanto, a partir de esta relación. La apertura visual de estos oratorios al presbiterio se materializó mediante sendos arcos abiertos en el muro del presbiterio. Estas aperturas fueron anuladas como consecuencia de las restauraciones llevadas a cabo en el s. XIX, tal como se puede apreciar por sus improntas en el muro. En el caso de la capilla de los Tocino, quedó solo un acceso muy pequeño que lo comunica con la anexa casa rectoral, hoy casa hermandad de la Santa Vera Cruz, y cuyo uso hasta el año 2015 fue el de almacén de enseres.

La capilla tiene una planta cuadrada cubierta con una bóveda estrellada ochavada de nervios de piedra y plementos de ladrillo sobre una potente cornisa, capiteles y columnillas suspendidas situadas en los rincones.

\footnotetext{
Las coordenadas geográficas son $36^{\circ} 41^{\prime} 10.4{ }^{\prime \prime} \mathrm{N}-6^{\circ} 08^{\prime} 32.4$ ” O
} 
El paso de la planta cuadrada a la ochavada se produce mediante cuatro potentes trompas de ladrillo, y originalmente todo el conjunto estuvo revestido, lo que se deduce de los escasos restos que se conservan.

Exteriormente presenta un volumen prismático pétreo sin decoración, de aspecto militar. Solo un pequeño rehundido a modo de alfiz enmarca un hueco en forma de saetera situado en su fachada a la calle San Juan, que aparecía cegado por un tabique de ladrillo. Sobre este volumen se eleva el trasdós de la cúpula que cubre la capilla, semioculta tras un pequeño pretil de ladrillo. El prisma total tiene $8,74 \mathrm{~m}$ de alto y $6,85 \mathrm{~m}$ de ancho, quedando más bajo que el presbiterio y la casa anexa, y más alto que la nave de almacén. Las dos construcciones anexas a ambos lados de la capilla aprovechan constructivamente sus muros como elementos de carga y cerramiento.
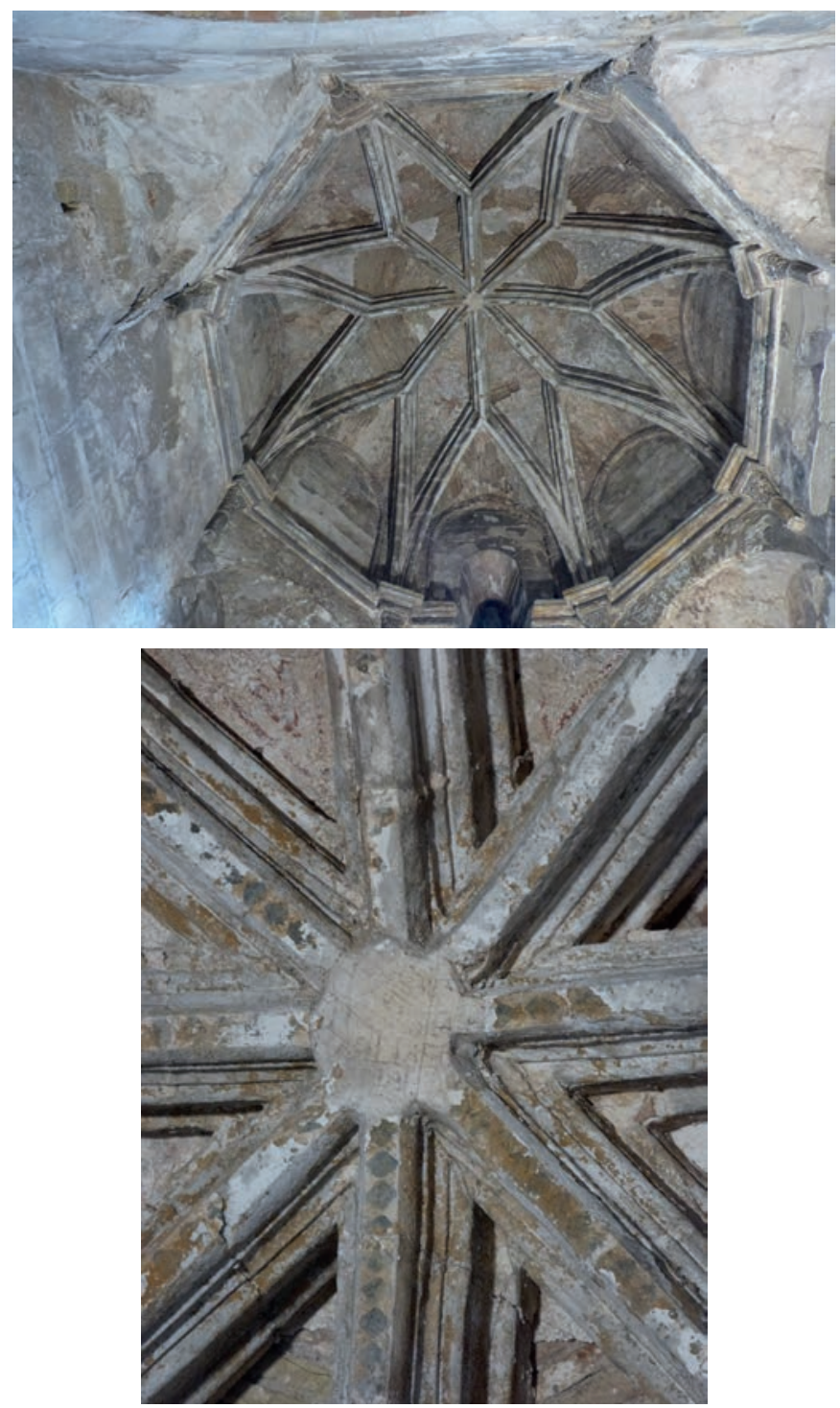

Figuras 1, 2, 3 y 4 . Imágenes de la capilla en su estado inicial.

\section{PLANTEAMIENTO METODOLÓgICO}

Partiendo de los antecedentes expuestos, y marcando como horizonte la consolidación constructiva de los problemas estructurales de la capilla, la eliminación de humedades y la recuperación de su espacio, se planteó la necesidad de determinar previamente sus valores patrimoniales y las causas de sus lesiones. Ambas cuestiones estaban ligadas al reconocimiento de la capilla como una unidad edilicia compleja, donde las huellas de las diversas transformaciones aparecen de forma sincrónica. Por otro lado, se planteó la premisa de que toda intervención supone un momento muy especial en la vida del edificio, pues permite acceder a elementos habitualmente ocultos y observar muy de cerca detalles que normalmente pasan desapercibidos. Si a esto añadimos la posibilidad de
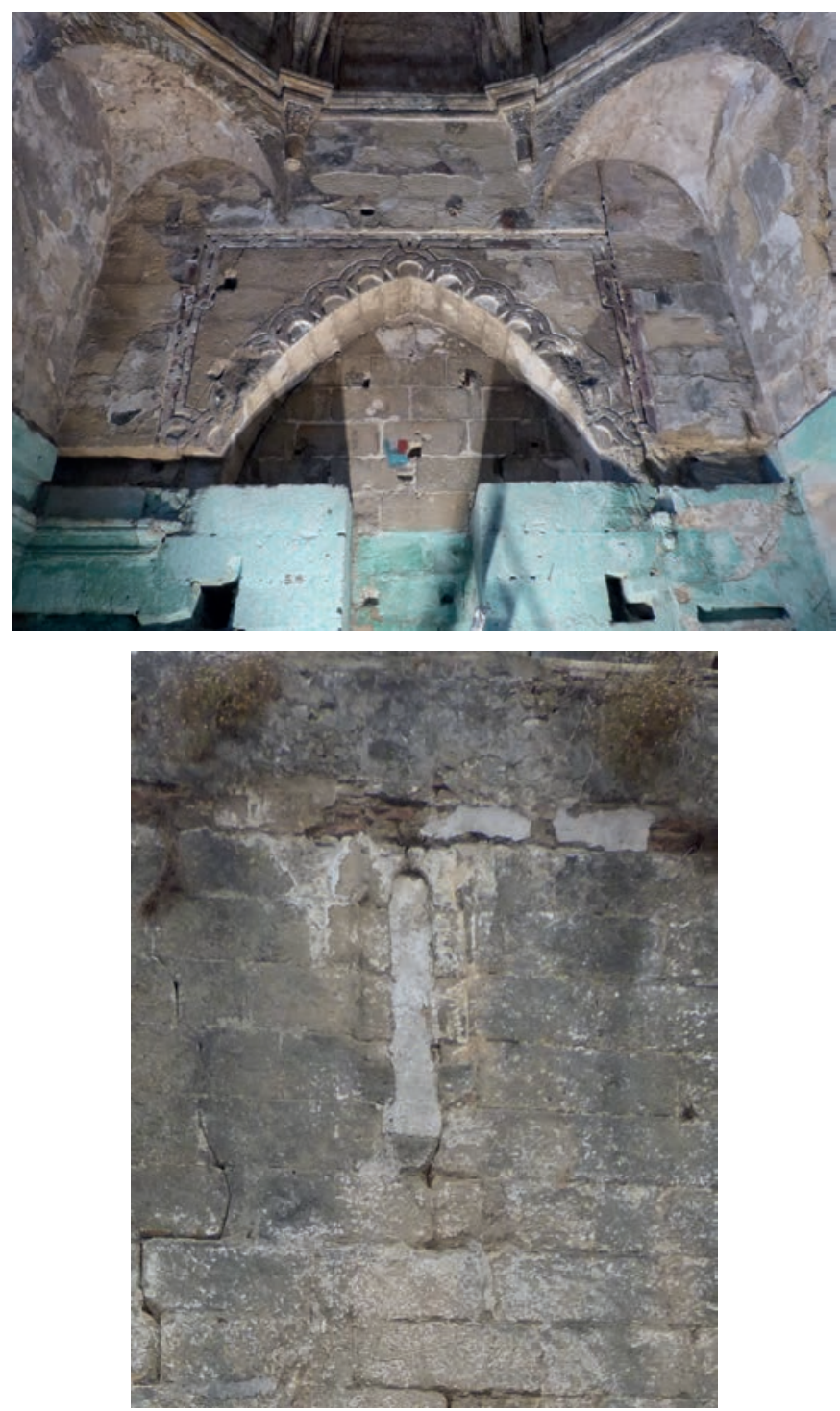


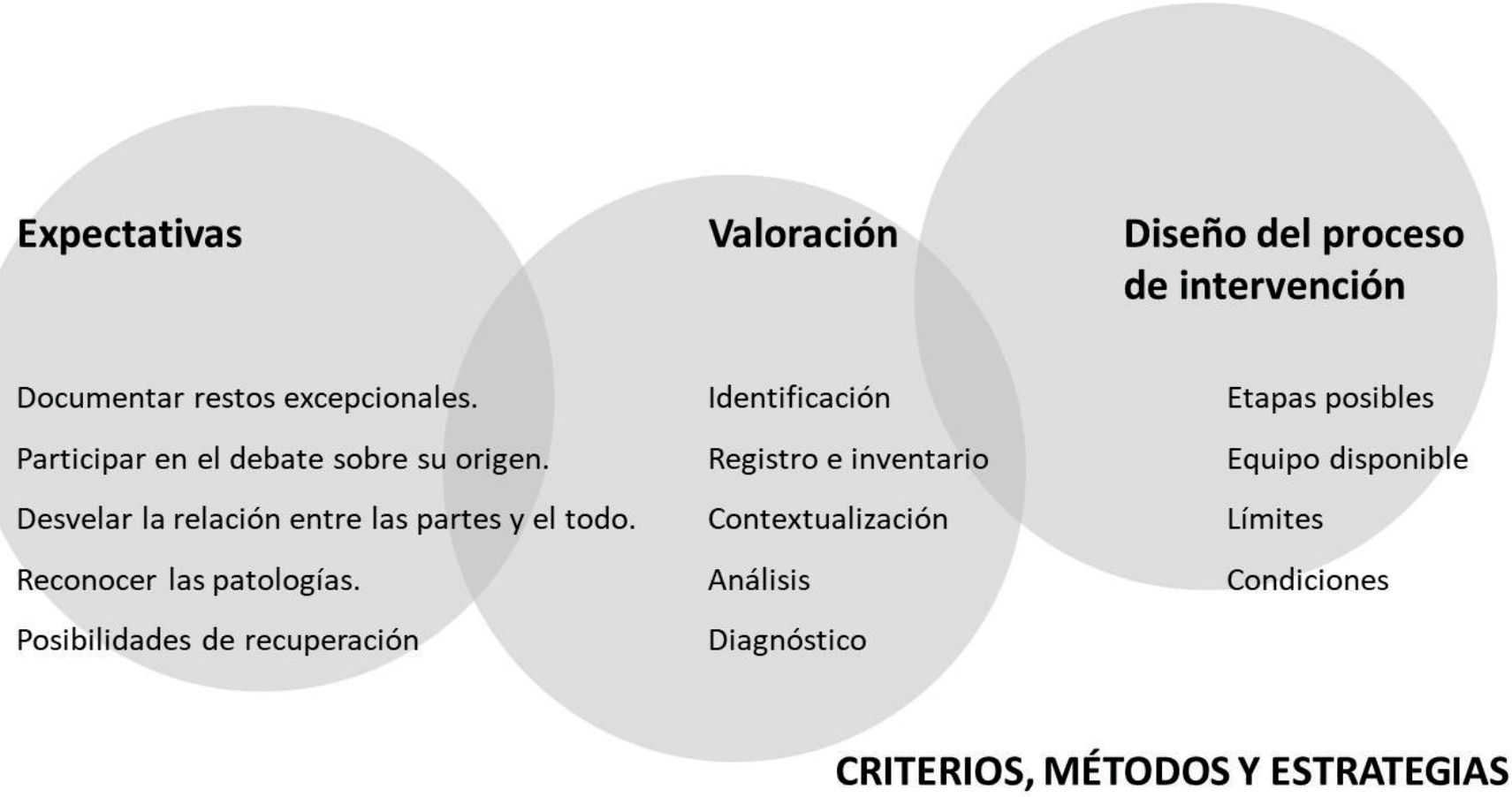

Figura 5. Diagrama del proceso de intervención.

modificación que toda intervención implica, es preciso establecer mecanismos para registrar cada una de las incidencias y peculiaridades que se puedan detectar en este proceso, con objeto de evitar pérdidas de significados. De este modo, se pretende garantizar la trazabilidad de todo el proceso. Esta cuestión viene reclamándose ya desde antiguo ${ }^{6}$, y aún no está sometida a una normalización precisa y efectiva. Para cumplir estos objetivos básicos se plantearon dos fases en la intervención?

En una primera fase que denominamos "trabajos previos", se abordó una revisión de los registros documentales existentes - desde las fuentes directas a las fuentes bibliográficas-, se llevó a cabo un levantamiento gráfico riguroso del que carecía el edificio, un registro de huellas y marcas visibles, un inventario de elementos ornamentales, así como la identificación de sus daños, y la lectura paramental a partir del estado actual. Estos

\footnotetext{
${ }^{6}$ Basta recordar la opinión de Torres Balbás: "No es frecuente la publicación de descripciones de las obras de conservación y restauración realizadas en nuestros antiguos monumentos por los arquitectos encargados de tan delicada misión, ni creo que en los archivos oficiales existan informes y diarios de ellas -vicio ya de larga fecha- que serían utilísimos para su estudio, pues nadie como el técnico que dirige esos trabajos está en condiciones de ver aspectos y detalles singularmente reveladores para el conocimiento íntimo de los monumentos restaurados y, por consiguiente, de la arquitectura española" (Torres Balbas 1946).

${ }^{7}$ Este método de trabajo ya quedó recogido en otras intervenciones anteriores como las realizadas en la iglesia de San Miguel de Morón de la Frontera (Pinto y Guerrero 2009; Pinto 2013).
}

trabajos se complementaron con un análisis del comportamiento estructural para lo que fue necesario realizar un modelado de la capilla a partir del levantamiento que se sometió a diversos comportamientos estáticos que se definieron a partir de los datos obtenidos del estudio arqueológico y el análisis constructivo (Compán et al. 2016; Pachón et al. 2016; Romero et al. 2018). Para realizar todos estos trabajos se montó un andamiaje que sirvió además para preconsolidar los restos de pinturas murales que se mostraban altamente degradados y podían peligrar por el efecto de los trabajos posteriores de consolidación estructural y limpieza general. De esta fase se obtuvo una información de gran valor para poder abordar la intervención posterior, tanto la arqueológica como la arquitectónica. Para finalizar, apoyada sobre los datos anteriores, y una vez desmontados los andamios, se realizó una excavación arqueológica que ocupó toda la superficie interior de la capilla y una zona en el exterior de la fachada, y que tenía como objetivo desvelar las estructuras subyacentes, interpretar las grietas actuales y valorar el impacto real de los refuerzos practicados en el s. XIX que estaban muy someramente descritos en los documentos históricos.

En una siguiente fase que denominamos "trabajos paralelos", se intensificaron los primeros, registrando $\mathrm{y}$ analizando aquellos elementos que iban quedando a la vista tras los trabajos de limpieza, desmontajes 


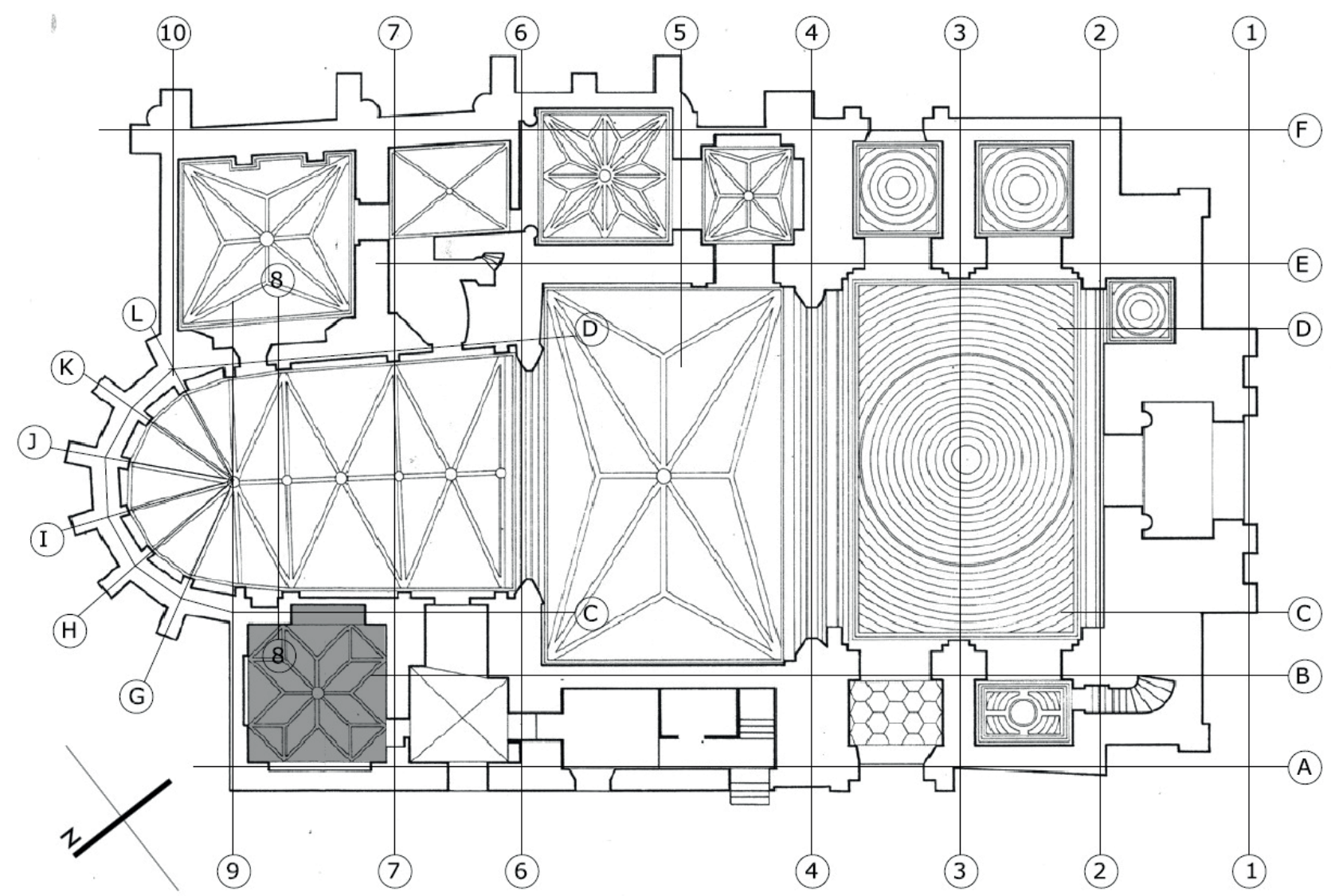

Figura 6. Sistema de referencia de elementos constructivos. Planta de la iglesia.

y sustituciones parciales de sillares. Estos trabajos se desarrollaron durante toda la ejecución de la obra, sirviendo de garante de la documentación de cada una de las huellas o restos que fueran surgiendo en el proceso, y de parámetros de corrección de la intervención inicialmente proyectada. Todos estos hallazgos e incidencias quedaron reflejados en un informe final donde se valoran e interpretan el conjunto de los datos resultantes ${ }^{8}$.

En los apartados siguientes relacionamos someramente las pautas metodológicas de cada uno de estos trabajos, para entrar posteriormente a profundizar en aquellos destinados a la lectura diacrónica del edificio, y concluir con la incidencia de esta última en su comprensión constructiva y en el diseño del proyecto de intervención.

\footnotetext{
${ }^{8}$ En la actualidad, los autores participan en un proyecto del Plan Nacional del Ministerio de Economía y Competitividad (HAR2016-78113-R) trabajando sobre la implantación de toda esta información ordenada y sistematizada a un modelo digital de información HBIM donde quedará accesible tanto para su conocimiento como para su tutela.
}

\subsection{Un sistema de referencia espacial común}

Con objeto de facilitar la identificación espacial de cualquier elemento constructivo o información obtenida desde las diversas disciplinas que necesitábamos integrar, se definió un sistema de coordenadas común tomando como líneas de referencia los muros y los tramos de nave. La referencia resultante se extendió a todo el edificio y se expresa en el esquema adjunto, donde las líneas corresponden a ejes de pilares adosados, o las caras interiores de muros, siguiendo el criterio habitual de diseño en planta de este tipo de edificios ${ }^{9}$.

\footnotetext{
${ }^{9}$ La indicación de la capilla de los Tocino sería A-C-7-9, que abarca toda su superficie. Para un elemento paramental, por ejemplo, la pared del arcosolio, indicaremos 9-A-C, siendo el primer número el paramento, y los otros dos los muros que lo acotan lateralmente. Para un elemento puntual de la planta, por ejemplo, para identificar una columnilla de la esquina izquierda, sería 9-A. El indicativo (x) aporta orientación al paramento, es decir, el código que lo lleve indica paramento exterior. Si no lo lleva es interior. En el caso de la capilla, para determinar los puntos de la bóveda ochavada, hemos añadido la referencia de los planos del ochavo. Así, para localizar uno de los capiteles indicaremos 9-N, poniendo primero el muro en el que está, y luego el plano del ochavo. El arco del ochavo, es decir, el frente de la trompa a la que pertenece este capitel sería N-9-C.
} 


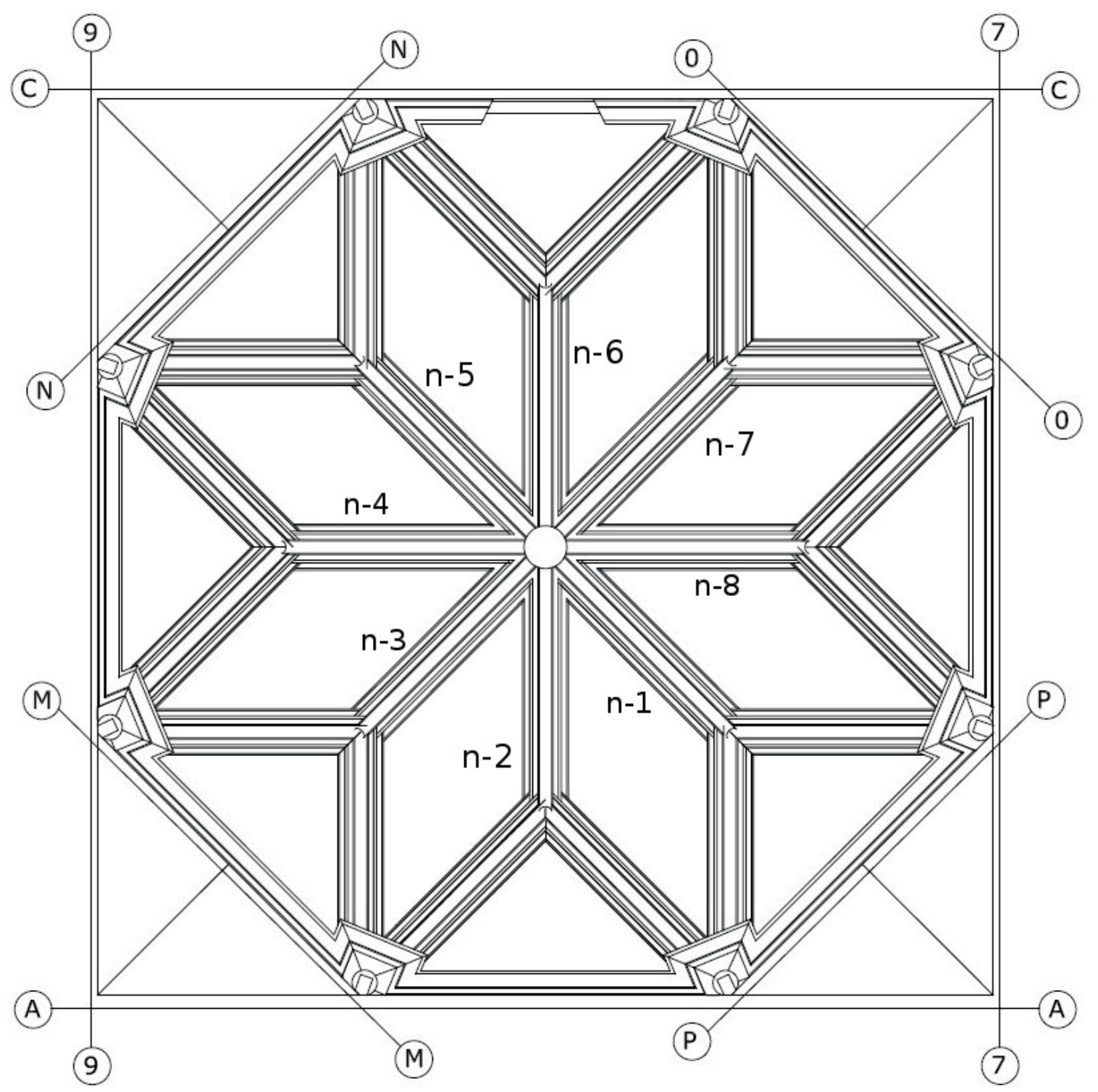

Figura 7. Sistema de referencia de elementos constructivos. Planta de la capilla.

Esta nomenclatura fue usada en todos los trabajos desarrollados y en los informes parciales y finales, aportando claridad a la identificación y registro de todos los elementos, y en obra permitió establecer un lenguaje común entre los oficios.

\subsection{El registro documental}

Antes de la intervención se realizó una revisión de los últimos trabajos historiográficos, sobre el documento fundacional de la capilla (Jácome y Antón 2007), sobre el contexto arquitectónico gótico mudéjar local y la interpretación de la capilla dentro del mismo (López 1999, 2014), sobre las intervenciones decimonónicas en el edificio (Álvarez et al. 2003) y los más recientes de M. Barroso sobre el análisis arquitectónico y constructivo de algunos elementos de la Iglesia ${ }^{10}$. La interpretación historiográfica anterior a estos trabajos insistía en que la capilla era consecuencia de la reforma de una qubba inicial en la que se había sustituido una bóveda esquifada por otra de traza gótica al inicio del siglo XVI. Esta hipótesis se sustentaba en la identificación de esta capilla como aquella en la que, en 1285 se produce la firma de

\footnotetext{
10 Trabajo Fin de Máster leído en el Master de Arquitectura y Patrimonio Histórico de la Universidad de Sevilla por Manuel Barroso Becerra en 2012, titulado Aproximación a las parroquias fundacionales de Jerez de la Frontera. La torre escalera de la iglesia de San Juan de los Caballeros: un nudo de complejidad arquitectónica. Trabajo inédito.
} 
una carta enviada a Sancho IV por los caballeros jerezanos ante el asedio de la ciudad. Aunque las fuentes que narran este legendario suceso (Rallón [c1660] 2003: 133; Mesa ([1754] 1888: 144), no señalan el lugar del templo en el que se produjo, a finales del siglo XIX a raíz de la restauración de la iglesia, se comenzó a identificar la capilla de los Tocino como escenario del mismo, conociéndose desde entonces como capilla de la Jura ${ }^{11}$.

Los datos disponibles, más otros nuevos aportados durante este trabajo por el historiador López VargasMachuca, han sido recopilados y ordenados, configurando una cronología que ha servido de indicador de partida para establecer la temporalidad de la secuencia de los acontecimientos constructivos obtenidos a partir de la lectura paramental y su referencia a los sucesivos espacios, funciones y construcciones. Estas relaciones han servido también para reconocer los puntos de mayor conflicto constructivo, ubicando temporalmente el origen de algunas de las grietas y patologías existentes.

11 «San Juan de los Caballeros». El Guadalete, 4 de septiembre de 1890.

\subsection{EI levantamiento gráfico}

Partimos de un levantamiento topográfico del perímetro del edificio realizado por el servicio técnico del Ayuntamiento de Jerez. Estos datos permitieron estacionar varias bases topográficas desde las que se obtuvieron las coordenadas de puntos, tanto en el exterior como en el interior del edificio ${ }^{12}$. Estos sirvieron de referencia para el enlace de las distintas capturas fotográficas de las superficies de la capilla: en el caso de los paramentos mediante ortofotos ${ }^{13} \mathrm{y}$ en la caso de la bóveda, mediante fotogrametría digital convergente $^{14}$. Esta captura masiva de puntos ha permitido obtener gráficos vectoriales mediante programas de

\footnotetext{
12 Se ha empleado una estación Leica FlexLine plus TS02 con alcance de $400 \mathrm{~m}$ de medición sin prisma; precisión en la medida a prisma de 1,5 mm de 2 ppm y de $2 \mathrm{~mm}$ de 2 ppm a cualquier superficie.

${ }_{13}$ Nickerson ASRix V.2.0 Digital Image Rectifier. http://nickerson.icomos. org/asrix/asr.htm (página web consultada el 10 de julio 2009)

${ }^{14}$ A partir del proceso de un conjunto de fotografías obtenidas con cámara digital de alta resolución calibrada se obtuvo una nube de puntos situados en el espacio con el apoyo de la toma de datos con topografía, Wu, Ch. 2011: "VisualSFM: A visual structure from motion system», "VisualSFM: A visual structure from motion system", http://ccwu.me/vsfm/ (consultado el día 22 de noviembre de 2014).
}
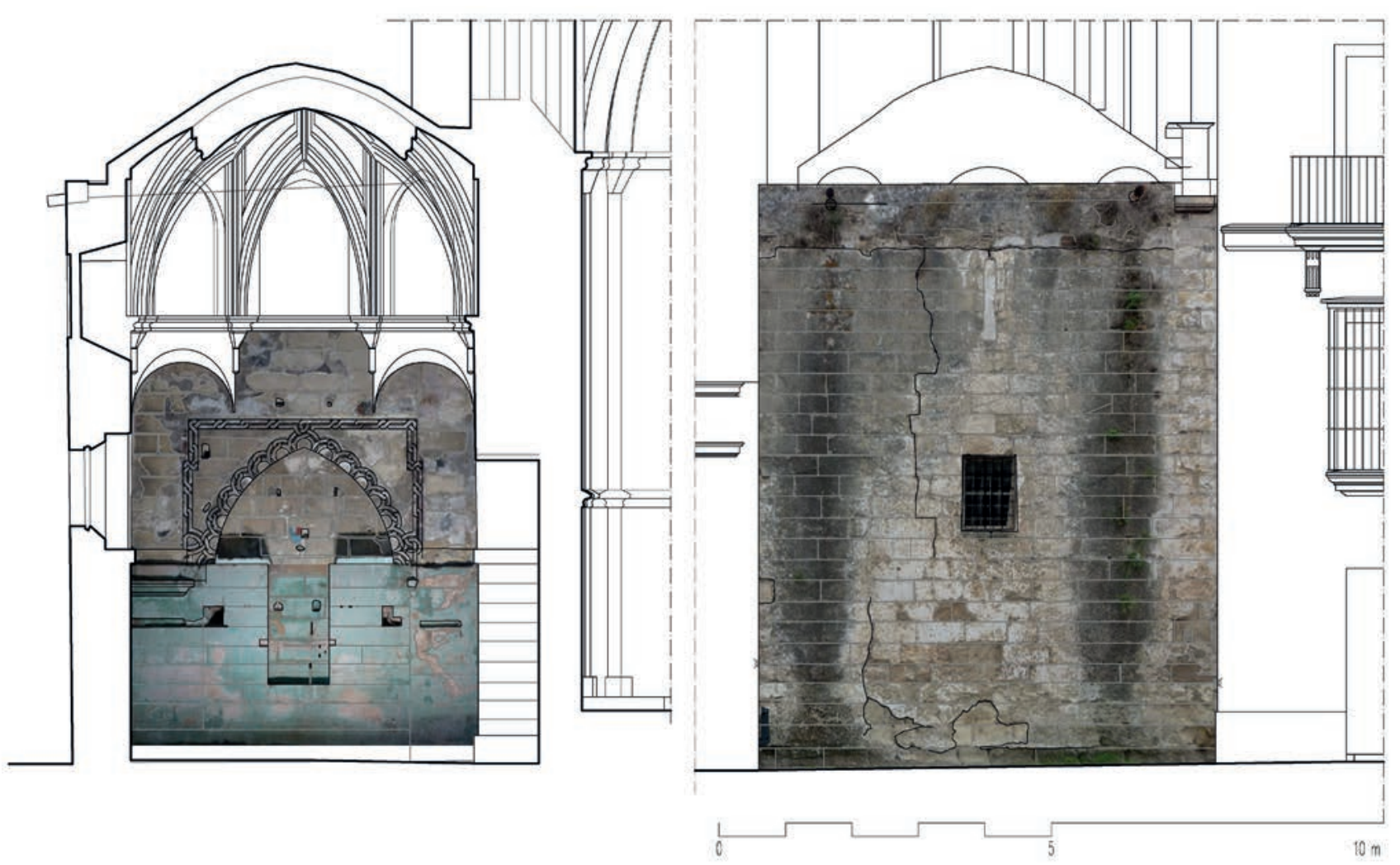

Figura 8. Paramentos 9-A-C y A-9-7 obtenidos a partir de ortofotos. 


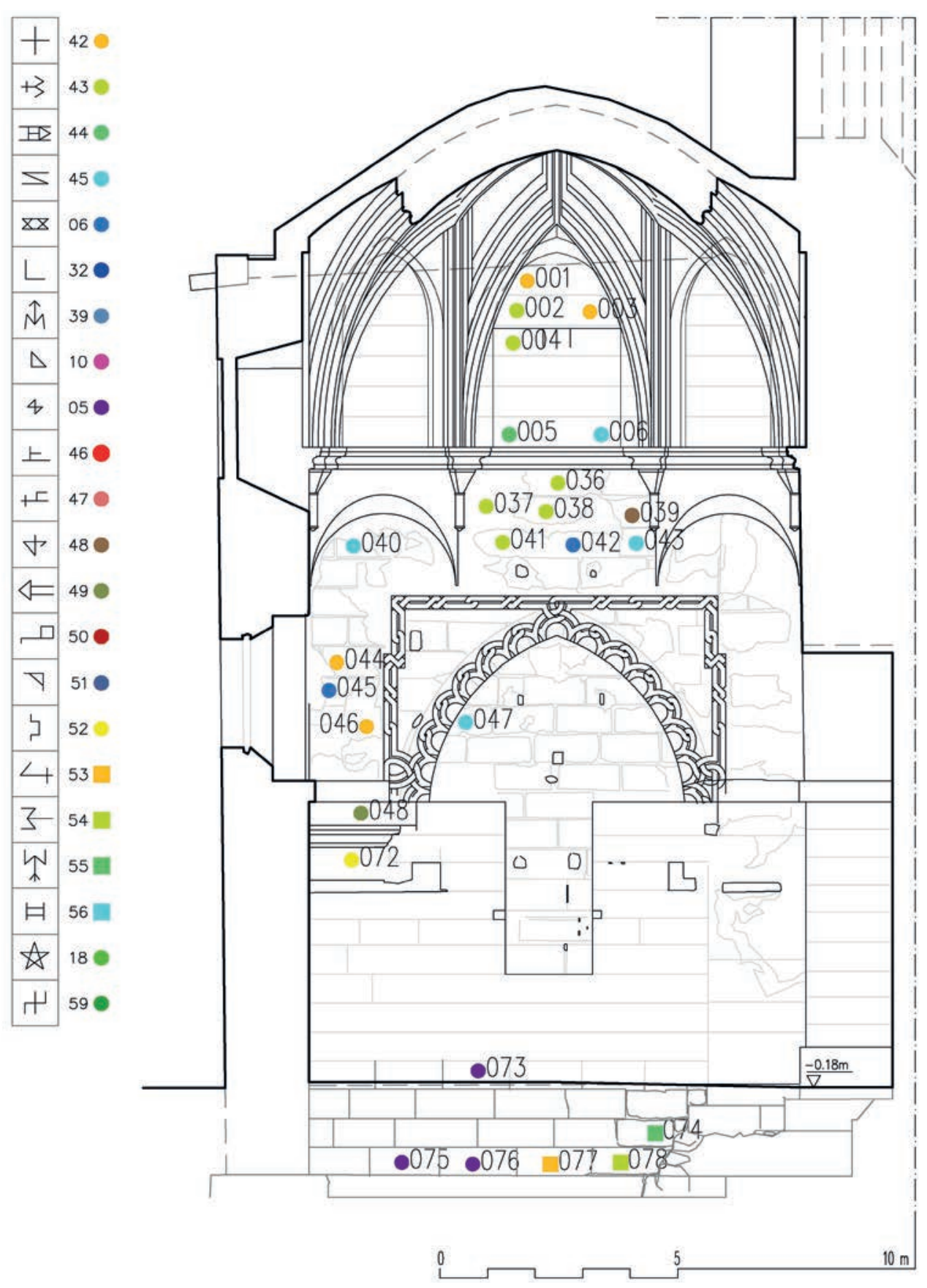

Figura 9. Identificación y mapeado de marcas de cantero en el paramento 9-A-C del interior de la capilla.

dibujo asistido por ordenador ${ }^{15}$, que traducimos a dibujos convencionales en proyecciones planas - planta, alzados y secciones-, útiles para representar los diversos análisis y localizar espacialmente cada uno de los datos elaborados. Del mismo modo, estos datos métricos sirvieron para modelar la capilla digitalmente y parametrizar sus elementos constructivos, obteniendo

\footnotetext{
${ }^{15}$ En concreto se usó el programa AutoCAD de la firma Autodesk.
}

visualizaciones descriptivas de aquellos elementos más complejos como la bóveda.

\subsection{El análisis gliptográfico}

Los paramentos de piedra de la capilla mostraban numerosas señales o marcas que suelen ir asociadas a procedimientos constructivos y a la presencia de canteros, 


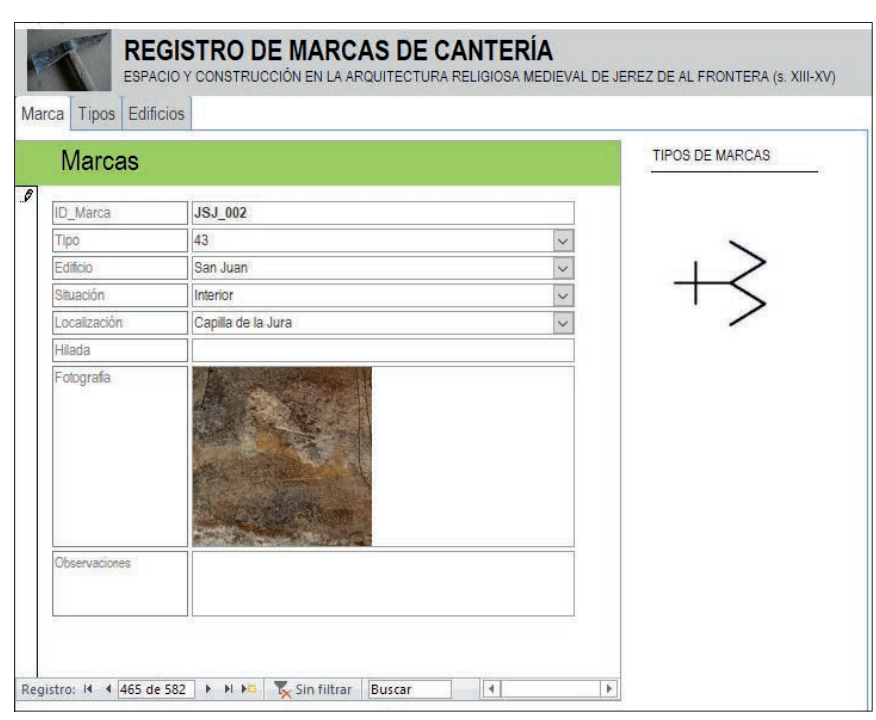

Figura 10. Ficha de registro gliptográfico (marca 002, tipo 43).

situándonos en un ámbito edilicio determinado. La presencia de estas marcas ya fue advertida en algunos estudios sobre la capilla, aunque las recogidas pertenecían solo al conjunto del templo (Jácome y Antón 2007). Su identificación se completó una vez montados los andamios para la inspección y consolidación de las pinturas murales. Con objeto de facilitar su registro, cada una de estas marcas quedaron descritas en fichas semejantes a las usadas para los elementos decorativos, y representadas en planos específicos que las localizan ofreciendo un mapa de las cuadrillas o equipos que trabajaron en la obra desde los cimientos hasta el cierre de la bóveda ${ }^{16}$. Estas marcas además, permiten relacionar este edificio con otros coetáneos en los que también se han localizado, lo que nos informa de talleres y cuadrillas locales que podemos vincular a los tipos de materiales, canteras y alfares, o caracterizar tipológicamente sistemas de labra y ornamento ${ }^{17}$. López Vargas-Machuca ya adelantó en su trabajo la existencia de un taller de maestros jerezanos que desarrollaron su actividad por toda la región (López 2014).

\subsection{El análisis estratigráfico constructivo}

El análisis de la estratigrafía subyacente se realizó a continuación de la lectura paramental, como resultado

\footnotetext{
${ }^{16}$ La metodología empleada es la misma que se aplicó en el estudio de la torre Atalaya en Jerez de la Frontera, perteneciente al mismo período histórico (Guerrero 2009).

${ }^{17}$ Estas relaciones han sido analizadas en Guerrero Vega, 2019.
}

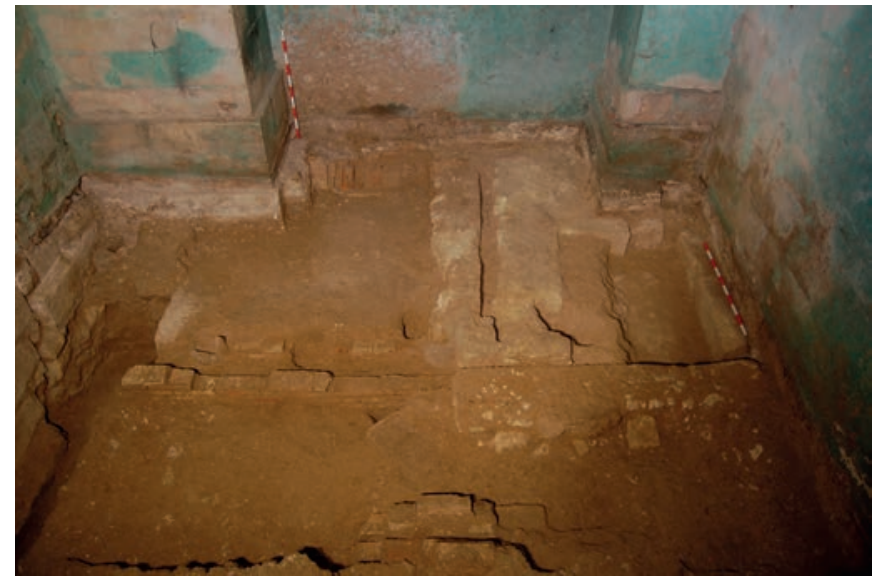

Figura 11. Fotografía general de la excavación.

de una tramitación independiente ${ }^{18}$. Dicha actividad se ha centrado en el estudio de los niveles y estructuras subyacentes hasta una profundidad que ha alcanzado una media de $0,60 \mathrm{~m}$ desde la rasante definida en el nivel de acerado en el acceso de la antigua casa rectoral, siguiendo las pautas estratigráficas registradas a través del estudio geofísico realizado previamente ${ }^{19}$. El método de análisis estratigráfico de construcciones históricas que se ha utilizado surge como aplicación del estratigráfico arqueológico al estudio de los edificios históricos ${ }^{20}$.

El estudio paramental se relacionó con el resto de estudios (históricos, de trazado geométrico, patológicos, tipológicos, gliptográfico, iconográficos, de materiales...). Por lo tanto, el método seguido pretende no convertir cada uno de estos análisis en un compartimento estanco dentro de la investigación global del edificio. Se propone, por tanto, la utilización de un método ágil pero sistemático, en el que es muy importante la sencillez y la claridad tanto de la toma de datos como de los análisis posteriores. Con este objetivo se han simplificado algunos procesos presentes en los referentes antes expuestos expresándose en los resultados que desarrollamos posteriormente. Debemos destacar que su desarrollo ha sido imprescindible para determinar el

\footnotetext{
${ }_{18}$ Es uno de estos desajustes administrativos que van en dirección contraria a la incentivación de un trabajo interdisciplinar, al igual que sucede con la gestión de los proyectos arquitectónicos de intervención patrimonial como si fueran de nueva planta. En este caso, como intervención arqueológica preventiva, se autorizó por resolución de 26 de noviembre de 2014 de la Dirección General de Bienes Culturales de la Junta de Andalucía (Ref. exp.:061/ $\mathrm{PR} / \mathrm{CA} / 14)$ previo informe favorable de la Delegación de Cultura de Cádiz, proceso al margen de la tramitación del proyecto de intervención.

19 "Campaña de exploración geofísica mediante geo-radar". Estudio previo para un plan director. Iglesia San Juan de los Caballeros. Junio de 2011. (Informe 40047177-ANE-03.0), realizado por la empresa Vorsevi S.L.

${ }^{20}$ Nos referimos al conocido como "Método Harris de registro arqueológico" (Caballero 1995; Tabales 2002).
} 


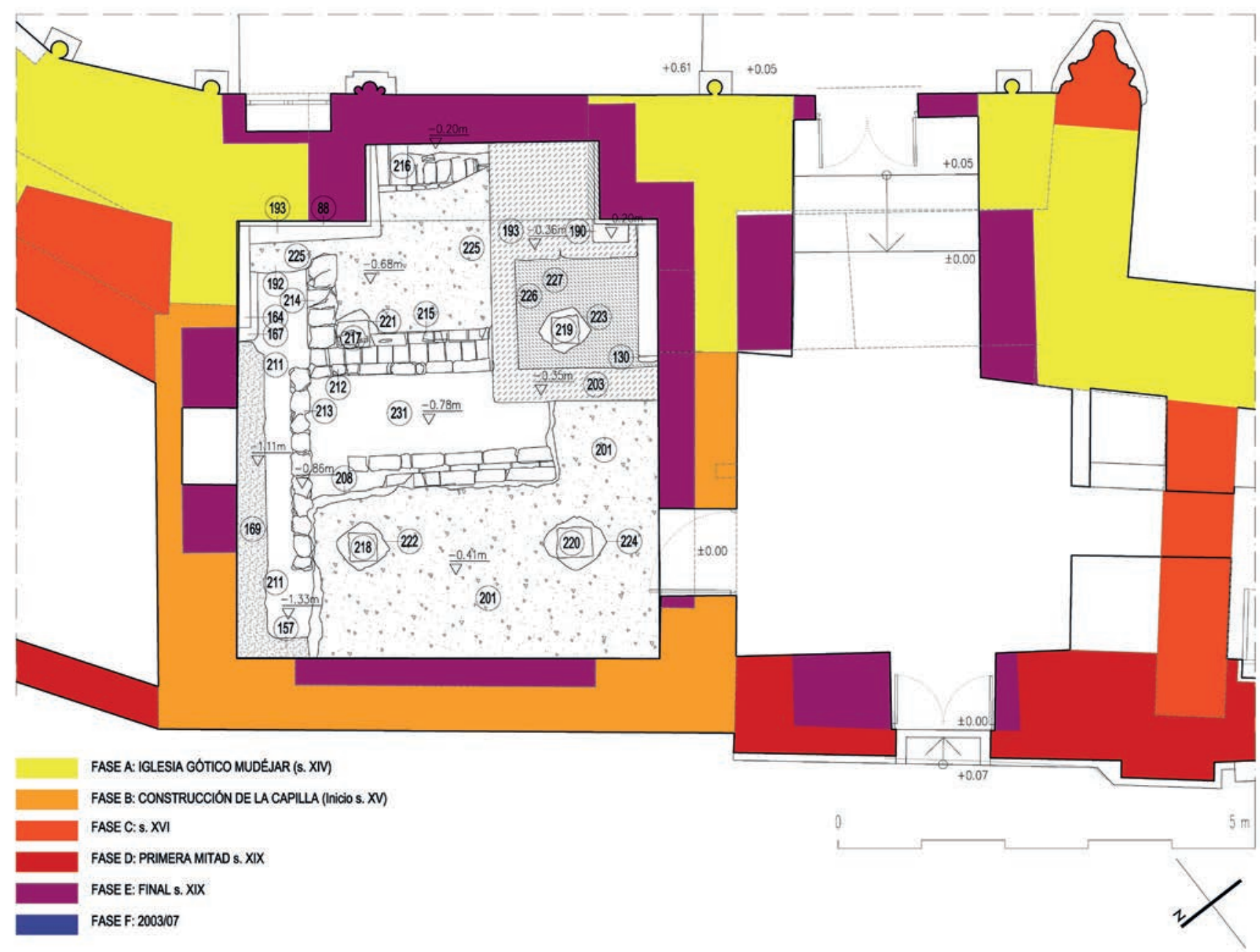

Figura 12. Planta de la excavación con las unidades estratigráficas.

impacto de la intervención decimonónica y para interpretar muchas de las patologías, consecuencia en gran medida del propio diseño y proceso constructivo de la capilla y de las reformas de otros elementos cercanos.

\subsection{El análisis geométrico y sistemas de control formal}

Partimos del hecho de que toda obra arquitectónica es resultado de un proceso predictivo o proyectivo que se ajusta y adapta, durante la fase de ejecución material, a las contingencias del lugar y sus circunstancias económicas, sociales y culturales. En cada época este proceso de proyecto y fábrica permite transitar desde la idea de un promotor en conjunción a la de un maestro o arquitecto, hasta su materialización, en la que además participan numerosos operarios. Este proceso requiere de diversos mecanismos de control formal, desde los que servían de intermediarios entre promotor y maestro a aquellos que transmitían las órdenes dadas por estos últimos en obra. De todos ellos será el medio gráfico, aplicado sobre el propio edificio o en soportes ajenos a ellos, el que alcanzará un mayor desarrollo (Jiménez y Pinto 2003: 121-129). El dibujo de traza es el más habitual, al reflejar el orden y la medida de los elementos que posteriormente serían levantados o elevados hasta conseguir la materialización del volumen. Por desgracia son escasas las trazas conservadas de este periodo, pero en el propio edificio a veces quedan huellas de su traslación a la obra o pueden deducirse de la lectura atenta de la planta o alzado obtenida del levantamiento. En este caso podíamos reconocer sin excesiva dificultad cómo la planta de la capilla está claramente condicionada por la separación entre los estribos del ábside al que se adosa, obteniendo una dimensión de 5 x 5 metros interiormente, aproximadamente $6 \times 6$ varas castellanas $(0,83 \mathrm{~m} / \mathrm{v})$, 
unidad de medida usual en el contexto edilicio entre los siglos XIV y XVI.

La intención de construir un espacio cuadrado es evidente dada la regularidad de sus dimensiones y está muy condicionada por el tipo de capilla de carácter funerario que se estaba produciendo en esta época, heredera de las antiguas qubbas islámicas (Ruiz 2012: 139). En este caso las reminiscencias del modelo islámico están patentes en las trompas de la bóveda, lo que llevó tradicionalmente a plantear que fuera inicialmente una configuración espacial con bóveda de paños lisos reformada para introducir una bóveda estrellada en una época más tardía. El rechazo a esta interpretación, ya expresado con anterioridad (López 2014: 73), se apoya ahora en el análisis paramental y constructivo. Hoy día podemos afirmar que la elección de formulaciones góticas o islámicas hibridadas en las bóvedas es bastante frecuente, y dependía no solo de una imposición tipológica, sino de la raigambre con la tradición constructiva local y de la presencia de material pétreo y de ladrillo (Alonso y Martínez 2011: 117).

Con estos antecedentes, y a partir del levantamiento gráfico, se comprobó la geometría que habría permitido el trazado de la bóveda a partir de la planta cuadrada de la capilla, observando la diferencia entre un trazado teórico y el real, verificando el rigor con el que estaba ejecutado. No entraremos aquí a valorar los resultados obtenidos, pues ya han sido objeto de otro trabajo publicado (Mora y Guerrero 2015).

\section{RESULTADOS}

La comprensión de la complejidad del oratorio requirió de la consideración conjunta tanto del análisis del objeto en sí, como del conjunto del que forma parte: el ábside mudéjar, el tramo de nave tardogótica anexa, así como las edificaciones colindantes de la casa parroquial y la nave de bodega. Quiere esto decir que, aunque el estudio se centrará en los elementos constructivos de la capilla, es imprescindible hacer referencia al resto del edificio, con el que comparten estructuras y vicisitudes. Dada la complejidad de todo este conjunto, se delimitó el ámbito de actuación todo lo posible, reconociendo la información fundamental de estos elementos con los que se relaciona a partir de aquellas huellas que se percibían en sus paramentos, pues en este trabajo no se realizaron catas de registro externas a la capilla, excepto las practicadas a pie del muro de fachada. Por fortuna, pudimos consultar también los informes de seguimiento y las imágenes conservadas de la intervención arquitectónica realizada en 2006 en la casa parroquial anexa ${ }^{21}$.

Teniendo en cuenta la dualidad existente, el valor del edificio como estructura arquitectónica y como documento histórico, se han intentado alcanzar dos objetivos generales. En primer lugar, obtener un conocimiento sintético de su evolución constructiva, diferenciando los elementos que pertenecen a cada una de ellas, así como las sucesivas transformaciones llevadas a cabo. En segundo lugar, elaborar una descripción y documentación precisa tanto del estado del edificio que nos encontramos, como de la intervención desarrollada. Para ello, el registro fiel de todo lo acontecido es de una gran importancia, pues se sumará al conocimiento del edificio a partir de ahora.

De todos estos trabajos, dado el carácter de este número monográfico, profundizaremos a partir de aquí en el papel que asumió la lectura cronológica en la definición y desarrollo del proyecto de intervención.

\subsection{Lectura Cronológica}

\section{FASE A: Iglesia gótico-mudéjar s. XIV}

A este momento corresponde la construcción del ábside del templo [UE 6]. Se trata de una unidad constructiva formada por un muro poligonal de sillería, con estribos del mismo material, de tamaño y organización regular escalonados en altura. Se cubre con bóveda de nervios pétreos decorados con dientes de sierra y plementería de ladrillo, cuya magnitud, siguiendo un modelo extendido en el Jerez bajomedieval, se vincularía con su finalidad funeraria (Caramazana y Romero 2016). La relación estratigráfica con la capilla y las semejanzas formales con el ábside de la Real Colegiata de San Hipólito de Córdoba sitúan esta operación a finales del siglo XIV (López 2014: 73).

En la base del estribo 9-C, que no fue reforzado en el siglo XIX, se comprueba como la cimentación se resuelve con una mínima zapata formada por una hilada de sillares, levemente más anchos, sobre una zanja de mampostería irregular tomada con argamasa de cal que crece a medida que profundiza [UE 167]. No se ha podido determinar la potencia de este firme, que continúa por debajo de la cota $-1,60 \mathrm{~m}$.

\footnotetext{
${ }^{21}$ Agradecemos la documentación aportada por el estudio de Juan Luis Trillo de Leyva y Antonio Martínez García, arquitectos autores del proyecto y la dirección de las obras llevadas a cabo en la referida fecha sobre la antigua casa parroquial. También la consulta del estudio histórico para dicha intervención de Fernández González, L. 2006: San Juan de los Caballeros. Datos históricos para su historia material. Trabajo inédito.
} 


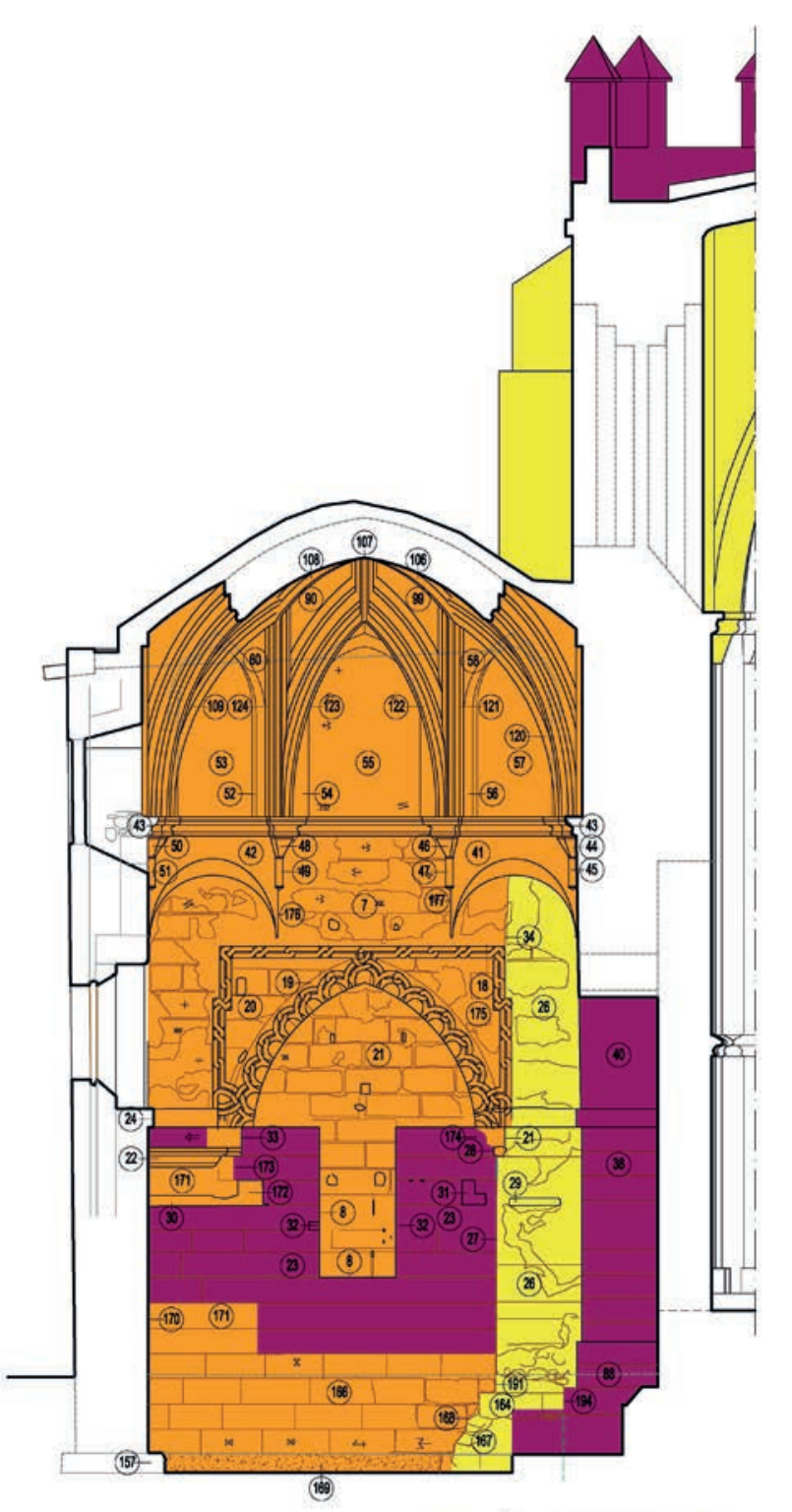

SECCIÓN 1-1' (PARAMENTO 9-A-C)

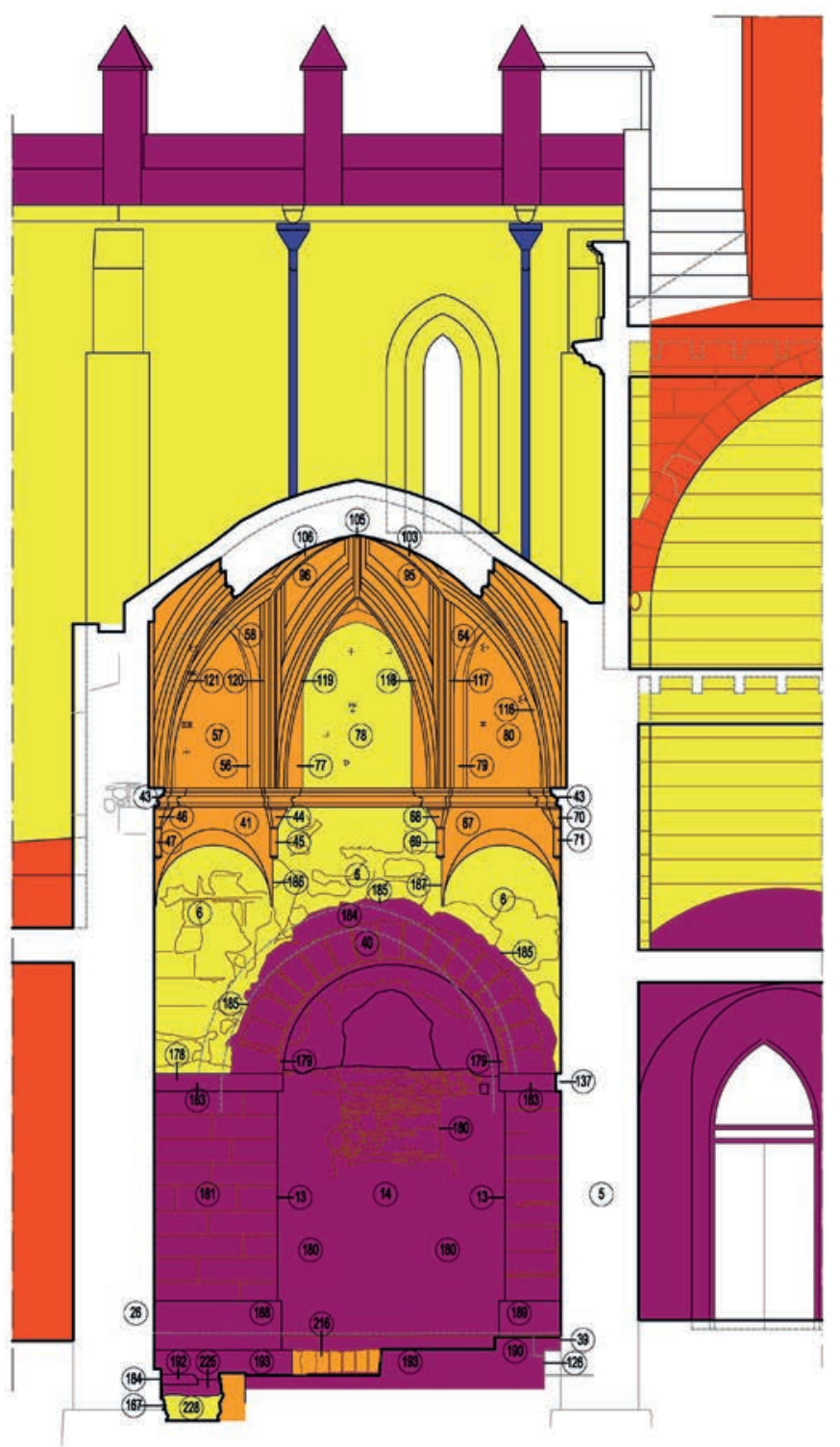

SECCIÓN 2-2' (PARAMENTO C-7-9)

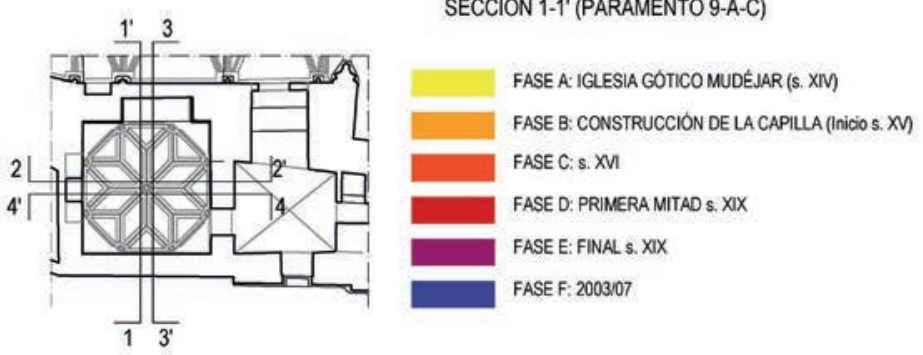

Figura 13. Lectura paramental. Secciones de la capilla 1 y 2.

En el transcurso de las excavaciones arqueológicas se pudo documentar el nivel de antropización del terreno, que llega como mínimo a unos $110 \mathrm{~cm}$ de profundidad respecto a la cota de solería de la casa parroquial. En esta cota se encuentran los primeros restos óseos correspondientes a un cementerio exterior al templo ${ }^{22}$, asociado al costado de la cabecera, mencionado en el Libro de Repartimiento de la ciudad

\footnotetext{
${ }_{22}$ El estudio de los restos óseos fue llevado a cabo por el Dr. D. Juan Manuel Guijo, identificándose aproximadamente 12 individuos. La situación del contexto, alterado por la propia zanja y cimentación de la capilla, hizo imposible su interpretación completa. En cualquier caso evidencian que la construcción del oratorio ocupó parte del cementerio exterior al templo.
} 


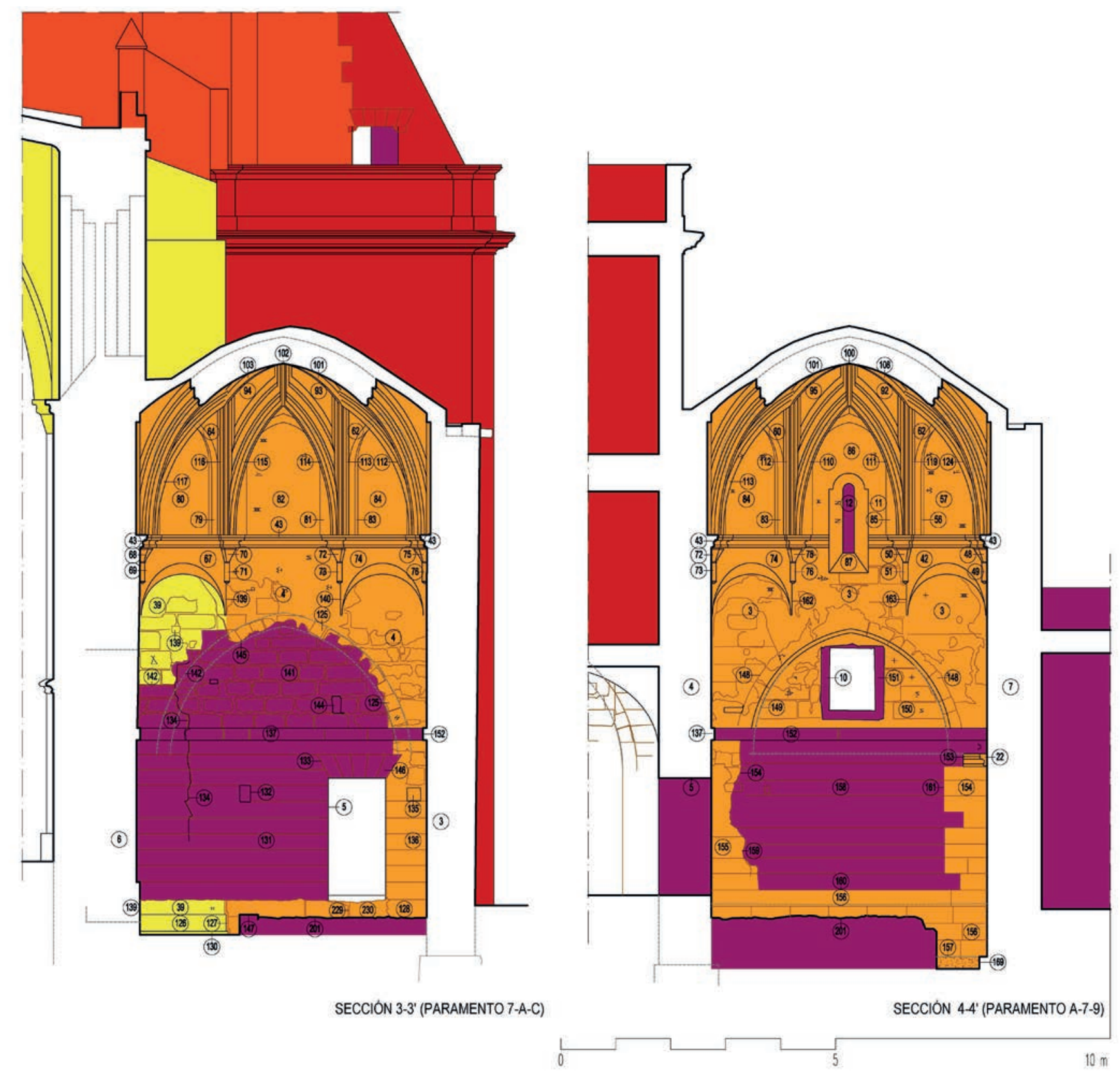

Figura 14. Lectura paramental. Secciones de la capilla 3 y 4.

(González y González 1980: 105)23. Este documento, se elaboró poco después de la toma de la ciudad por las tropas castellanas, fechada tradicionalmente en 1264 y recientemente retrasada en tres años (Borrego 2016). Los restos aparecían también fragmentados por el muro de sillarejo que cerraba las criptas de la capilla [UE 211].

\footnotetext{
${ }^{23}$ El ejemplar que se conserva es una copia del s. XIV.
}

FASE B: Construcción de la capilla. Principios s. XV

A lo largo del medievo, el interés de los nuevos promotores por conseguir espacios exclusivos con carácter funerario llevó a la aparición de capillas funerarias ad hoc (Bango 1992: 124), en ese contexto habría que entender la construcción de la capilla de $\operatorname{los}$ Tocino $^{24}$. Aunque su construcción fue datada en

${ }^{24}$ Sobre las capillas funerarias medievales en la ciudad véase Guerrero Vega, 2019 . 
1404, gracias al testamento de su fundador (Sancho 1934: 5) ${ }^{25}$, la localización de un traslado del testamento original del jurado Andrés Martínez Tocino, ha permitido además identificar correctamente a su fundador, y conocer tanto a los artífices de la obra como su coste ${ }^{26}$ :

... y devemos a Fernan Garzia Albañi, hijo de fernan $G^{\mathrm{a}}$. Albañi é a Diego frnz (Fernández) Albañi su sobrino cinco mill e seiscientos e sinquenta maravedis desta moneda usual, que fincaron por pagar de los diez e nueve mill maravedis por que con ellos me combine, que hisiesen la Capilla que yo fago en la Iglesia de San Juan desta Ciudad (Jácome y Antón 2007: 187).

${ }^{25}$ En esta publicación el autor establecía erróneamente que el fundador fue Andrés López Tocino.

${ }^{26}$ Archivo de Protocolos Notariales de Jerez de la Frontera (APNJF). Escribano público Alonso de Fuentes Cantillana. Oficio XVIII. Año 1738-39. Signatura 2443. Fecha 9/7/1739. Folio 133 vto. y 134.

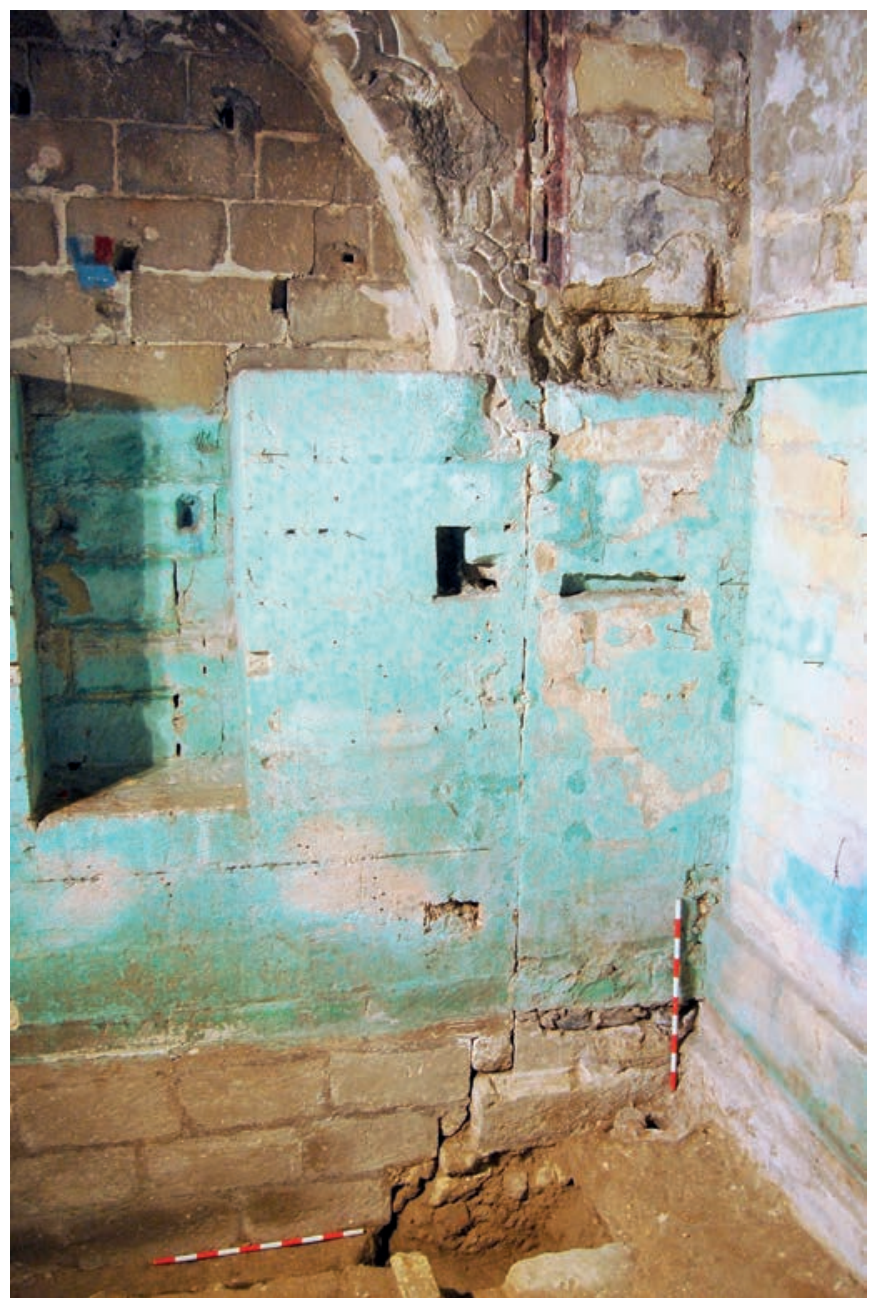

Figura 15. Adosamiento en 9-C.
La capilla se construyó anexa a la cabecera de la iglesia, aprovechando el espacio entre dos estribos y alineando sus muros laterales con estos. Aunque se empleó en ambos casos un aparejo de sillares, entre la fábrica primera y la de la capilla puede apreciarse una diferencia en la altura de estos, siendo los de la iglesia de $0,34 \mathrm{~m}$ de altura [UE 6] y $0,30 \mathrm{~m}$ los de la capilla [UUEE 3, 4, y 7]. La ejecución de ambos se lleva a cabo mediante dos hojas de cantería y relleno interior de mampuesto, tal como se aprecia en la rotura en el muro de fachada para la ventana abierta en el s. XX [UE 151].

Rompiendo el nivel antrópico donde se ha detectado el cementerio está la cimentación de la capilla, formada por una zanja de $1,50 \mathrm{~m}$ de anchura en cuyo fondo se colocó una base de cal y restos pétreos amalgamados formando un nivel de replanteo o nivelación de la cimentación. Sobre esta base se dispone una zapata corrida formada por hormigón de cal, arena y restos pétreos

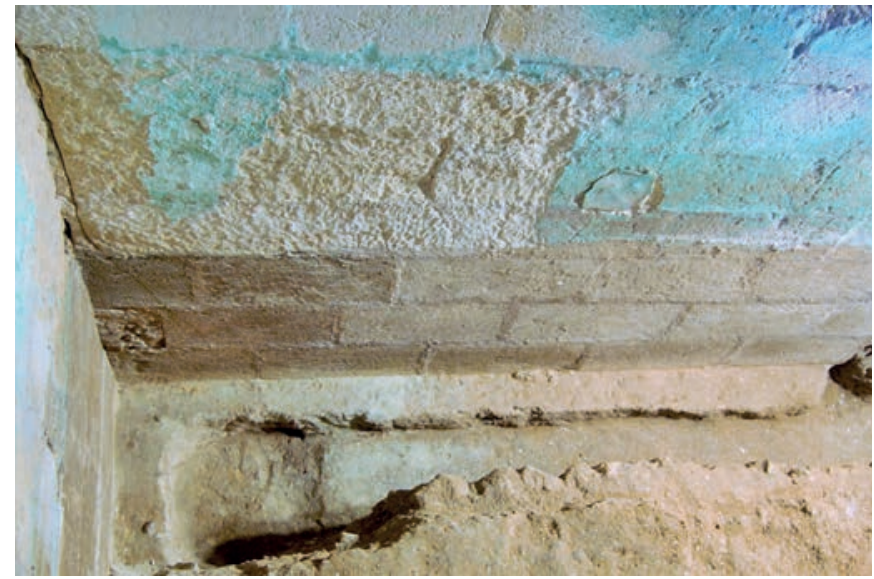

Figura 16. Base de la cimentación del muro 9-A-C.

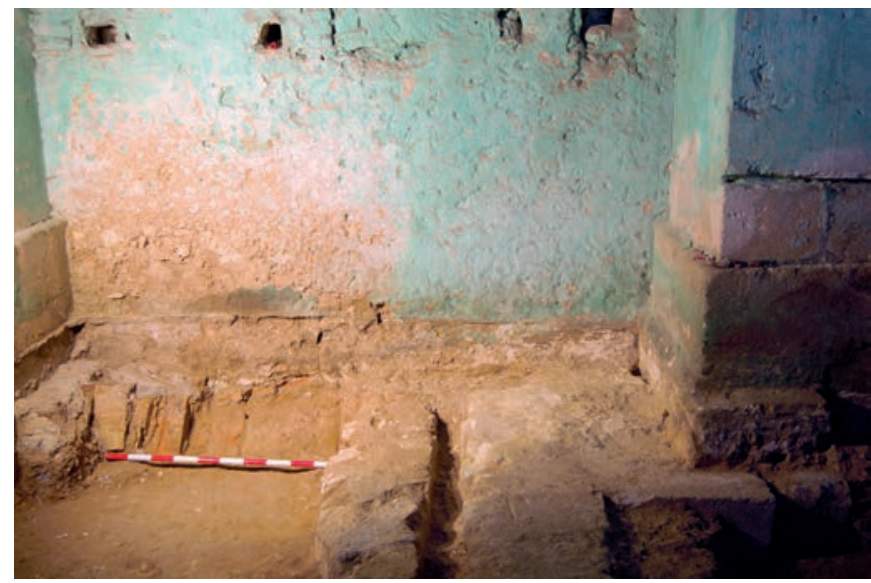

Figura 17. Construcción de la cripta en el cimiento del presbiterio C-9-7. 


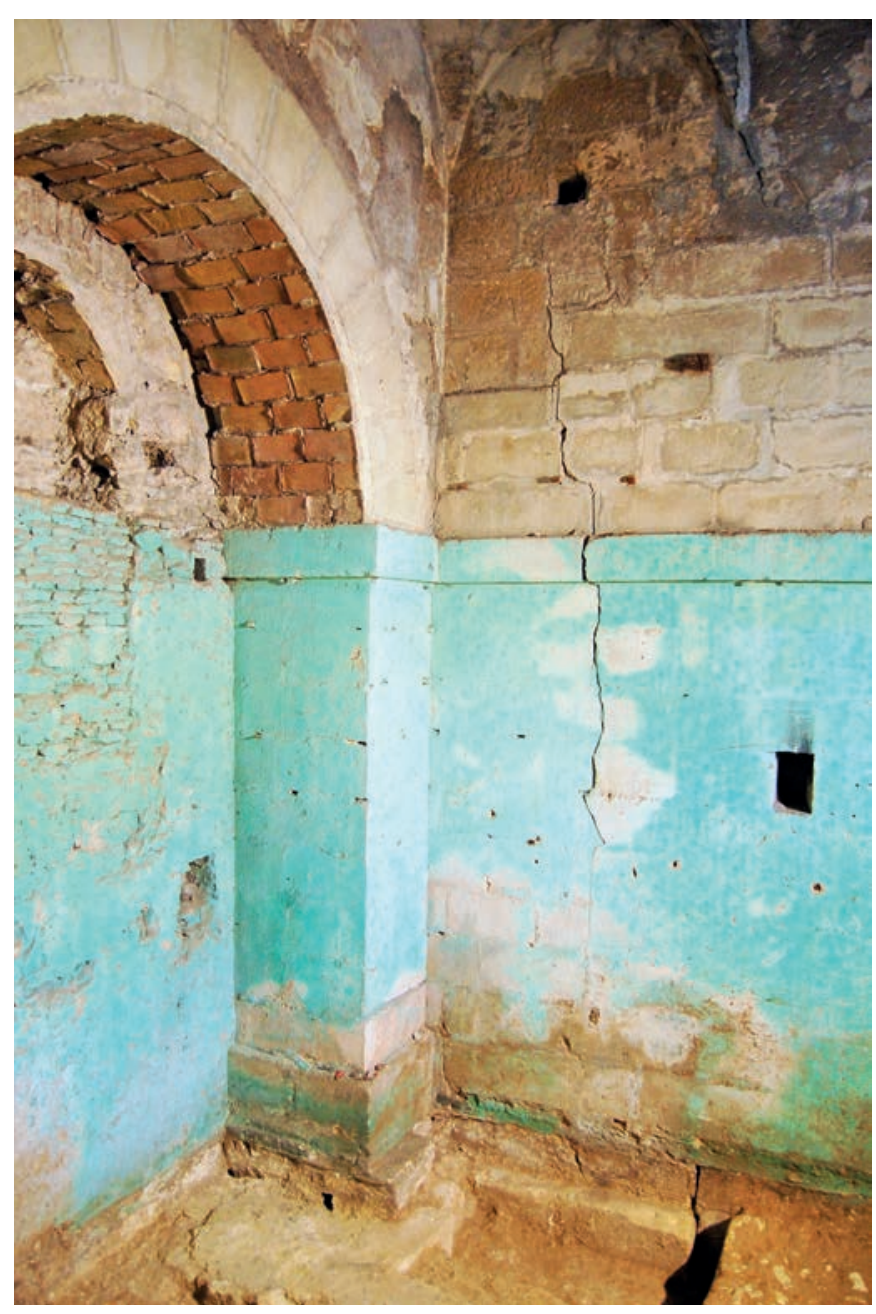

Figura 18. Adosamiento al estribo del presbiterio en 7-C.

que hace de nivelación del terreno [UUEE 169 y 157] ${ }^{27}$. A partir de esta arranca la primera hilada de sillares, a $-1,32 \mathrm{~m}$, que se eleva con el mismo ancho y aparejo de los muros, detectándose varias marcas de cantero idénticas a las existentes en las zonas altas de los muros, lo que nos habla de su unidad constructiva. El contacto entre la cimentación de la capilla y la del contrafuerte de la iglesia se produce por adosamiento.

En el interior del oratorio se ha documentado la existencia de tres criptas de enterramiento [tumbas 1,2 y 3 UE 202-204, 2012-16]. Estas tienen paredes laterales y bóvedas rebajadas de ladrillo, de las que solo se ha conservado, en algunas zonas, el arranque de la primera hilada curva ${ }^{28}$. Se ha conservado también el testero nororiental de estas cámaras, construido en mampuesto

\footnotetext{
27 Se ha podido documentar tan solo una profundidad de $0,30 \mathrm{~m}$ de esta zapata aunque su arranque se encuentra por debajo de esta cota.

${ }_{28}$ Sobre estos enterramientos estaría la solería, obteniendo así de forma aproximada el nivel original, pues debido a las intervenciones decimonónicas no ha quedado nada de él.
}

irregular. Las dimensiones de estos enterramientos son desiguales, encontrando dos de $0,90 \mathrm{~m}$ de anchura y otra mayor, situada en el umbral de la capilla desde la cabecera, de 1,20 m para cuya ejecución fue labrado el cimiento del muro del ábside.

En el muro 9-A-C, el adosamiento se aprecia en toda su longitud, y apenas presenta piezas de traba [UE 34]. En el arcosolio decorado, este coincide con el límite de la decoración del alfiz [UE 18] que se labra a caba1lo entre ambas fábricas. En el caso del muro opuesto 7-A-C, al ser mayor el estribo de la cabecera el ochavo se construyó sobre este coincidiendo el adosamiento con el capitel-ménsula N-7 [UUEE 70 y 71]. Además, el arcosolio de este paramento tuvo que modificar la fábrica del estribo ya que el primero [UE 125] invade el volumen del segundo [UE 139], aunque las operaciones de refuerzo decimonónicas [UE 131] han ocultado parcialmente esta relación.

El paramento A-7-9 que forma la fachada hacia la calle San Juan, ofrece una configuración muy parecida a las anteriores, aunque en este caso mantiene una mayor unidad constructiva al estar construido completamente en esta etapa. A raíz del arco que aún se diferencia volumétricamente, observamos el modo en que debió estar acabado el anterior, con una moldura baquetonada que recorre la arista del arco [UE 148]. En la parte superior, a la altura de la cornisa del ochavo, se abre una esbelta ventana abocinada [UE 11], que en origen era menor, arrancando sobre la cornisa [UE 43]. En algún momento posterior, para proporcionar mayor entrada de luz al interior, se aumentó su altura por debajo de dicha cornisa, tal y como se apreciaba en los laterales de la ventana, donde queda a la vista lo inacabado del corte de las molduras y el relleno interior del muro [UE 232] taponado solo por un revoco de cal. $\mathrm{Al}$ exterior, esta ventana contaba con un pequeño alfiz levemente decorado que no se había conservado en su totalidad por la erosión.

El paramento C-7-9, que corresponde al muro del ábside [UE 6], alojaba el arco de comunicación entre la capilla y el presbiterio del templo. El cegado de este arco, de dimensiones y forma semejantes a los otros dos arcosolios mayores, se aprecia aún desde el interior del templo, y se verifica al superponer las proyecciones del interior de la capilla y del paramento interior del ábside. Su trazado es incompatible con los elementos ornamentales de este último, introducidos en la restauración decimonónica, pues interrumpiría una de las columnas adosadas y una de las pequeñas portadas neogóticas. 


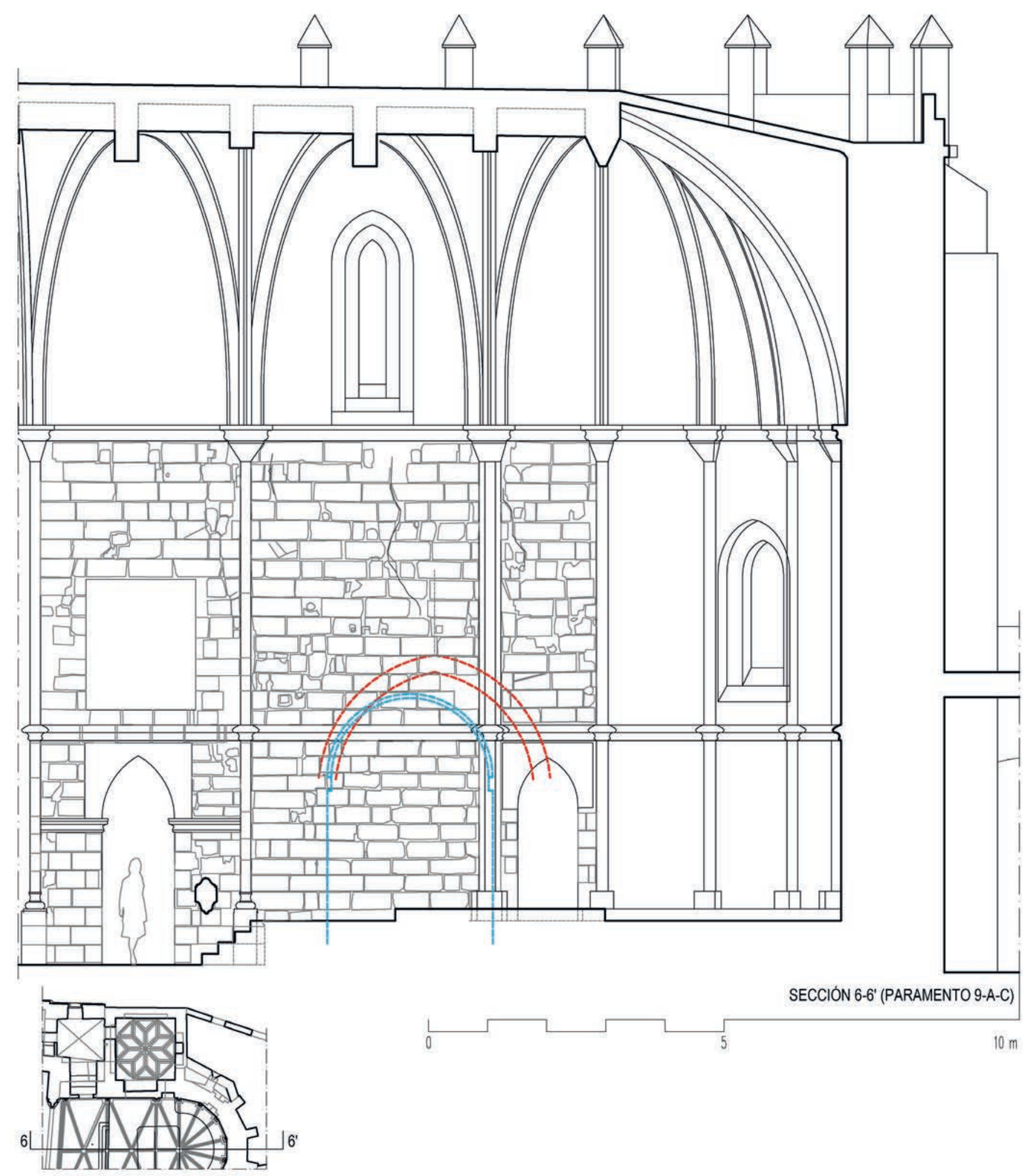

Figura 19. Alzado del paramento interior del ábside coincidente con la capilla. Se han indicado en líneas discontinuas de color azul la posición del arco interior de la capilla. En color rojo se representa una hipótesis del trazado del arco original. 
El arranque de la bóveda se formaliza en primer lugar por las trompas de arista [UUEE 41, 42, 67 y 74], que siguiendo la tradición mudéjar de hiladas aparejadas de ladrillo penetran en la fábrica de sillares, sirviendo las columnillas suspendidas de los vértices de elementos de transición. Sobre estas, la planta ochavada viene señalada por la cornisa de piedra que ocupa el espesor de la hoja interior de la fábrica [UE 43]. Los fondos de este ochavo que corresponden a los lienzos antes descritos son coplanarios a los mismos y mantienen la continuidad de su fábrica, sobre todo en el caso del ábside donde la moldura, las columnillas y capiteles suspendidos se injertan en la fábrica previa. Unos trazos incisos en la parte superior de la cornisa de piedra muestran el proceso de replanteo de la bóveda estrellada, cuyo trazado y construcción han sido analizadas en profundidad (Mora y Guerrero 2015).

A esta etapa pertenece también el programa pictórico que se ha conservado en este espacio. Este tipo de decoración ha desaparecido prácticamente de todas las capillas de este tipo coetáneas por intervenciones barrocas, decimonónicas y modernas. Por esta razón, los restos hallados aquí adquieren un especial valor documental. La ornamentación estaba formada por una sencilla y delicada

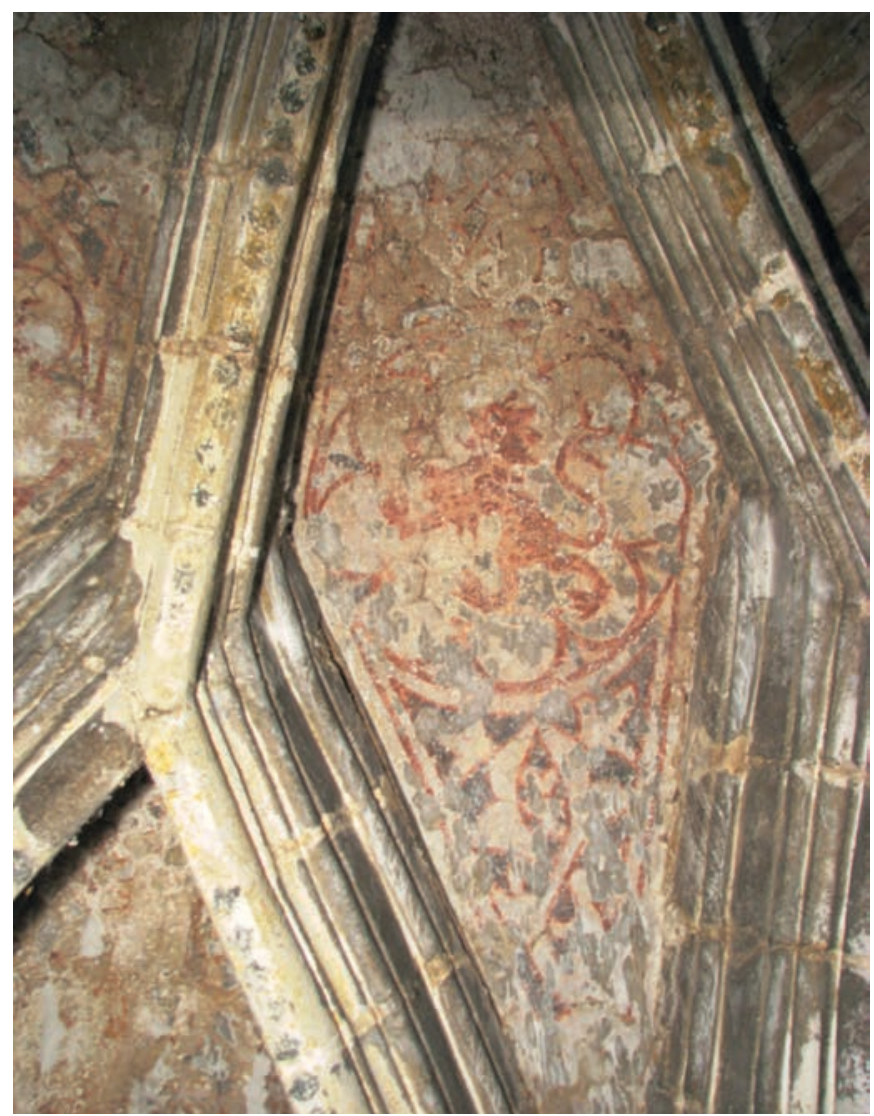

Figura 20. Plemento de la bóveda durante su restauración. geometría que recorre los cantos inferiores de los nervios y los arcos formeros de los ochavos, así como en una suave policromía de los capiteles. La parte más importante son los dibujos de los ocho plementos romboidales, que repiten el motivo de un león rampante enmarcado en lóbulos cuyo referente formal y simbólico ha sido también identificado (Mora y Guerrero 2015: 1130).

\section{FASE C: Las transformaciones de su entorno durante el s. XVI}

Un siglo después de concluirse la capilla, se comienza un proceso de reforma del templo que transformó radicalmente su nave. Se inició con la construcción de la bóveda de terceletes del tramo inmediato a la cabecera, en los primeros años del siglo $\mathrm{XVI}^{29}$. La consecuencia más importante será la construcción de los estribos de la esquina 6-C del nuevo tramo abovedado, ya que, debido a su gran envergadura, agotará el escaso espacio disponible entre esta

\footnotetext{
${ }^{29}$ La bóveda ha sido fechada en torno a 1530 (Pomar y Mariscal 2004: 62), aunque podría ser algo anterior teniendo en cuenta que ya en 1504 se cierra la bóveda de terceletes de la capilla mayor de la catedral de Sevilla muy parecida (Jiménez 2013: 233).
}

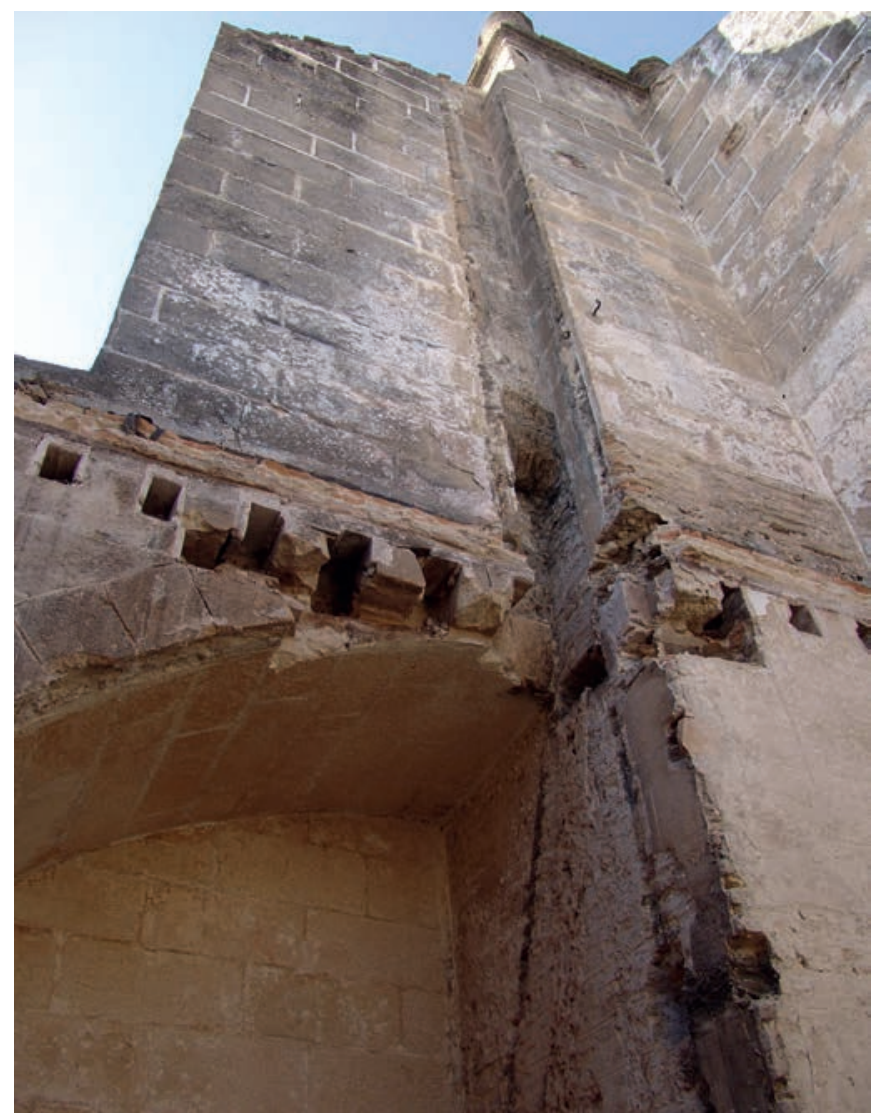

Figura 21. Estribo de la esquina 6-C durante las obras de restauración de la antigua casa parroquial (Trillo y Martínez, 2006). 


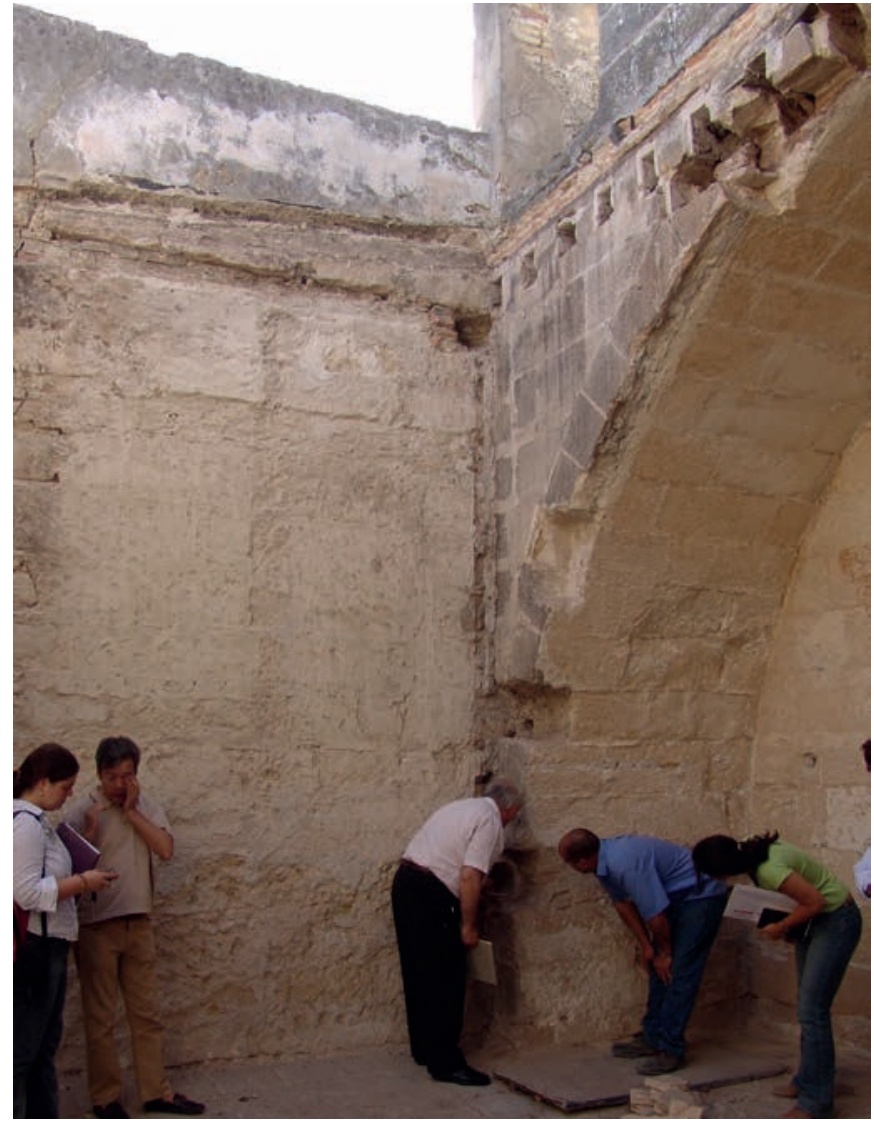

Figura 22. Estribo en su desvío hacia 7-C durante las obras de restauración de la antigua casa parroquial (Trillo y Martínez, 2006).

esquina y la capilla de los Tocino, y en la otra dirección avanzando hasta alinearse con la calle San Juan. El estribo quedará posteriormente oculto en la casa levantada en el s. XIX, pero pudo observarse en toda su dimensión durante la reforma de la casa parroquial llevada a cabo en 2006. Los documentos fotográficos de esta intervención han permitido dimensionar correctamente este elemento, reflejarlo en el levantamiento que aquí se presenta e incorporarlo al análisis paramental. El punto de apoyo de este estribo en su parte inferior explicará, como veremos más adelante, algunas de las grietas observadas en el interior de la capilla.

Algunos años más tarde de este último hito, la construcción de una capilla aledaña, constituye otro momento esencial de su complejo devenir histórico. En 1551 Diego Mirabal de Villavicencio solicitó autorización para erigir una capilla sobre la antigua sacristía del templo, una pequeña construcción que se encontraba adosada a la capilla de los Tocino (Jácome y Antón 2007: 194)30. En las

\footnotetext{
${ }^{30}$ En 1579 se han documentado trabajos para el revestimiento de la bóveda de ladrillo de la capilla y la construcción de un enterramiento (Jácome y Antón 2007: 189).
}

fotografias realizadas durante las obras de restauración de la Casa de Hermandad en 2006, se aprecia cómo por encima de la bóveda de cañón que da acceso a la iglesia se situaba la huella del arco previo. Además, en el muro de la capilla de los Tocino que limitaba con la de los Mirabal, se conservaba la huella del arco formero de la bóveda que nos proporciona la altura original de dicho espacio. De nuevo, estos datos obtenidos de fotografías fugaces de la intervención de 2006 nos han permitido registrar esta información y asociarla a la generada en nuestro proyecto.

Poco antes de la construcción de esta capilla se realizan otras en el lado simétrico respecto a la nave del templo, introduciendo modificaciones en la simetría del cuerpo principal; movimientos de cimentaciones, nuevas aperturas de arcos, etc., que pudieron tener unos efectos colaterales de los que no tenemos mucha más información. Por otra parte, se levantan construcciones adosadas a la fábrica principal, como el cuerpo adosado a la cabecera y a la capilla formada por un muro de sillería entre los estribos de la primera.

Obras de mantenimiento y reparo del templo ocupan lo que resta del s. XVI y los siglos XVII y XVIII, en lo que parece una actividad usual en este tipo de edificios, sin que podamos deducir nada especial de ellas (Aroca 2002: 226-245). Podemos considerar este periodo como de relativa estabilidad, aunque se siguen realizando construcciones como el último tramo de la nave o la torre fachada, suficientemente alejadas de la capilla como para relacionarlas con las huellas observadas en esta última. No se ha documentado en este período ninguna intervención sobre la capilla, a pesar de la inscripción descubierta en la clave de la bóveda (REEDIFICO ESTA CAPILLA EL $M^{\circ} M A \ldots$ ) [UE 88], que debía hacer referencia a obras de acondicionamiento como, por ejemplo, la instalación de un retablo en el arcosolio decorado del que se habían conservado huellas de su estructura, o el enjabelgado de color marrón claro cuyos restos indican que cubrían los nervios y molduras de la bóveda, amortizando la decoración original antes mencionada.

\section{FASE D: Reforma s. XIX. La construcción de la casa rectoral}

En 1819 la capilla de los Mirabal, dedicada en aquel momento al Santo Cristo de la Salud, amenazaba ruina. La parroquia solicitó entonces permiso para poder cegar el arco de comunicación con la iglesia y trasladar este 
oratorio a otra ubicación ${ }^{31}$. Los problemas se concentraban en el lugar donde limitaban las dos capillas y la iglesia, que recibía la carga del arbotante de la bóveda de terceletes de la nave levantada a inicios del s. XVI. Los problemas estructurales que presentaba fueron los que desembocaron en la construcción de la casa rectoral, hoy sede de la Hermandad de la Vera-Cruz de Jerez [UE 2].

Pero la construcción de la casa parroquial al iniciarse el s. XIX tendrá consecuencias importantes en la

${ }_{31}$ Archivo Histórico Diocesano de Jerez de la Frontera (A.H.D.J.F.) Fondo Hispalense, Serie Jerez de la Frontera, Sección Ordinario, caja 49, doc. n. 12: Expediente a instancia del clero de la parroquia de San Juan de los Caballeros, para que se pase el patronato, que gozan el Marqués de Villamarta y Marquesa de Casinas, a la capilla de Santa Ana, por el mal estado de la del Santísimo Cristo de la Salud. 1819. capilla de los Tocino, pues se levanta amortizando la vecina de los Mirabal, alterando los estribos de la ampliación tardogótica y remontando sus muros sobre los de la propia capilla. Su fachada se adosa al muro de la capilla en el punto 7-A, donde se aprecia en un cambio de materiales y revestimientos. Superada la cota de la fachada de la capilla, el muro de cierre de la casa se superpone al de la primera mediante un pequeño retranqueo que deja espacio a un pequeño pretil actualmente fragmentado [UUEE 341 y 342], pero que debió fundirse con el muro de la capilla. Este pretil queda levemente elevado respecto al nivel del último forjado de la casa, lo que es un indicio de adaptación a una estructura precedente que pretendió integrar capilla y casa en una misma fachada. En el dibujo de Alfred Guesdon de 1853 se aprecia la

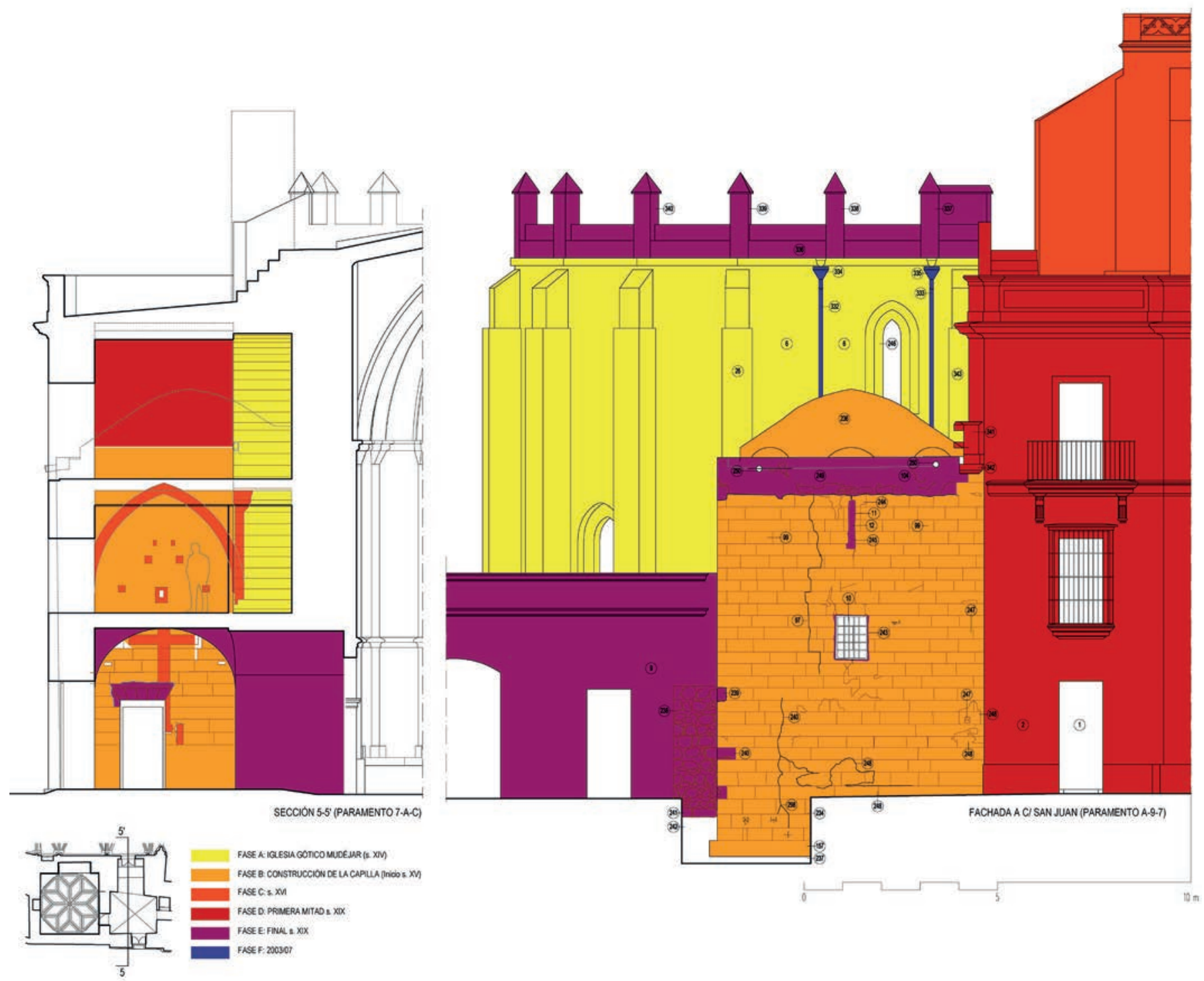

Figura 23. Lectura paramental. Alzado exterior de la capilla y alzado del paramento 7-A-C visto desde la sección de la casa parroquial. Se han situado las huellas de la capilla de los Mirabal obtenidas a partir de las fotos de la intervención de 2006. 
casa parroquial con la capilla adosada, ambas revestidas de blanco, donde la altura del muro de la segunda no supera la altura de la cornisa de la fachada de la casa ${ }^{32}$.

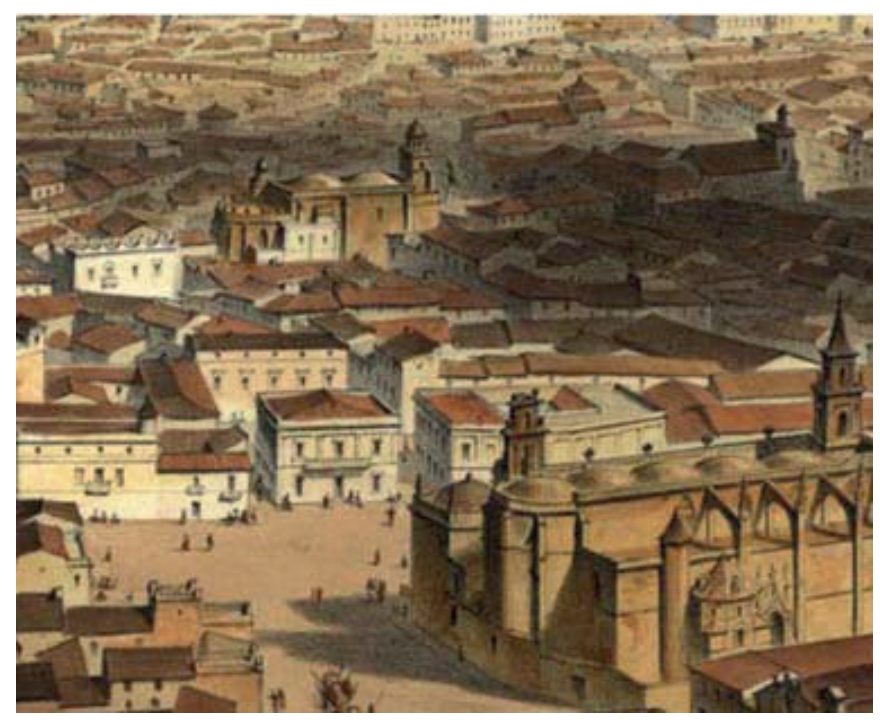

Figura 24. Detalle de la vista aérea de Jerez de la Frontera realizada desde el oeste por Alfred Guesdon. 1853.

\section{FASE E: Reforma S. XIX. La restauración de José Esteve y López}

Durante la segunda mitad del siglo XIX se realizaron en el templo distintas intervenciones de escasa importancia $^{33}$ (Álvarez et al. 2003: 106). Pero el precario estado de conservación y la amenaza de ruina del ábside motivaron en 1884 el inicio de unas obras de restauración que modificarían de manera notable la imagen interior del templo.

Dirigidos por el arquitecto local José Esteve y López, los trabajos dieron comienzo con la retirada del retablo del presbiterio y estuvieron condicionados por la continua falta de recursos económicos. Gracias al legado de Josefa de Bertemati la obra volvió a tomar impulso en 1890, año en el que ya se había restaurado el ábside cerrando los huecos originales que abrían a este de la capilla de los Tocino y la de los Carrizosa, se habían abierto las ventanas del ábside, se repusieron los baquetones adosados a los paramentos, se repararon las

\footnotetext{
32 Parece que el grabado se elaboró a partir de fotografías aéreas tomadas desde un globo aerostático (Gámiz 2004).

${ }^{33}$ En 1863 se recorrieron los tejados; en 1866 se realizan obras de albañilería, se recorren las bóvedas y se blanquea el interior de la iglesia; en 1868 y 1869 se verifican varias obras de albañilería y en 1871 se lleva a cabo una reparación en la sacristía.
}

bóvedas y se construyeron cuatro pequeñas portadas decoradas imitando el arcosolio de la capilla de los Tocino. (Álvarez et al. 2003: 107) ${ }^{34}$.

A este momento se deben una serie de operaciones destinadas al refuerzo de la estructura mural de la capilla que tratamos, sobre todo por el interior, así como el recalce en el subsuelo. De manera general se dispuso una nueva cimentación a base de un mortero de cal y cascote vertido en tongadas apisonadas de $0,15 \mathrm{~m}$ de espesor [UE 196]. Esta mejora del terreno, en algunos puntos con más de $0,70 \mathrm{~m}$ de profundidad, se practicó una vez superados los niveles de uso de la antigua capilla; es decir, eliminados su pavimento, abiertas las criptas y previsiblemente vaciadas ${ }^{35}$. Sobre esa superficie se dispone el vertido hasta alcanzar una cota de $-0^{\prime} 60 \mathrm{~m}$. Sobre ese nivel aparecieron diferentes capas de pavimento, en su mayor medida firmes de hormigón hasta la última solería de la que parte nuestra excavación.

Los esfuerzos se concentraron en el área de contacto entre la capilla y la cabecera. Para ello, en la práctica se reforzó el cimiento de todo este flanco, donde se abría el hueco original de la capilla. Para ello se abrió la cripta situada en ese punto y se maciza con hormigón prensado, sobre el que se dispuso un firme de mampuesto trabado con cal. Las jambas del arcosolio de medio punto construido en ese momento se reforzaron con sillares. Además, se recalzó el apoyo del estribo situado en el ángulo sudeste (7-C), ejecutándose un perímetro de sillares [UE 226] de 2,60 x 2,00 m, adosado a los muros, relleno con cascotes de piedra y cal apisonada [UE 227].

El refuerzo de los muros modificó la configuración de los paramentos interiores, mediante el cegado de los arcosolios con sillería de piedra. Para ello se emplea el mismo material, piedra de la cercana sierra de San Cristóbal, y aunque su formato es prácticamente el mismo, se aprecian en las interfaces cambios de verdugadas y alineaciones que marcan hasta donde llegó la operación.

Las molduras de imposta de los arcosolios originales fueron eliminadas casi en su totalidad, colocándose en su lugar una sencilla moldura prismática de piedra [UUEE 137, 152 y 183] que marcaba el arranque del

\footnotetext{
${ }^{34}$ La reforma del ábside, vino acompañada de la instalación en este de la sillería del coro, el cierre del presbiterio con un cancel de hierro y la erección de una mesa de altar con templete de estilo ecléctico. Estas operaciones parecen haberse realizado bajo las las pautas estilísticas y litúrgicas generales recogidas por el sacerdote, historiador, y arqueólogo Francisco Mateos Gagos (Pomar y Mariscal 2001, 96).

${ }^{35}$ En esa intervención se debió eliminar cualquier resto decorativo de las tumbas, de modo que en la excavación no se localizaron fragmentos de lápidas o decoraciones semejantes.
} 
arco de medio punto construido en el muro C-7-9. En este paramento, la sustitución de los sillares abarca toda la altura desde la citada moldura y la cimentación.

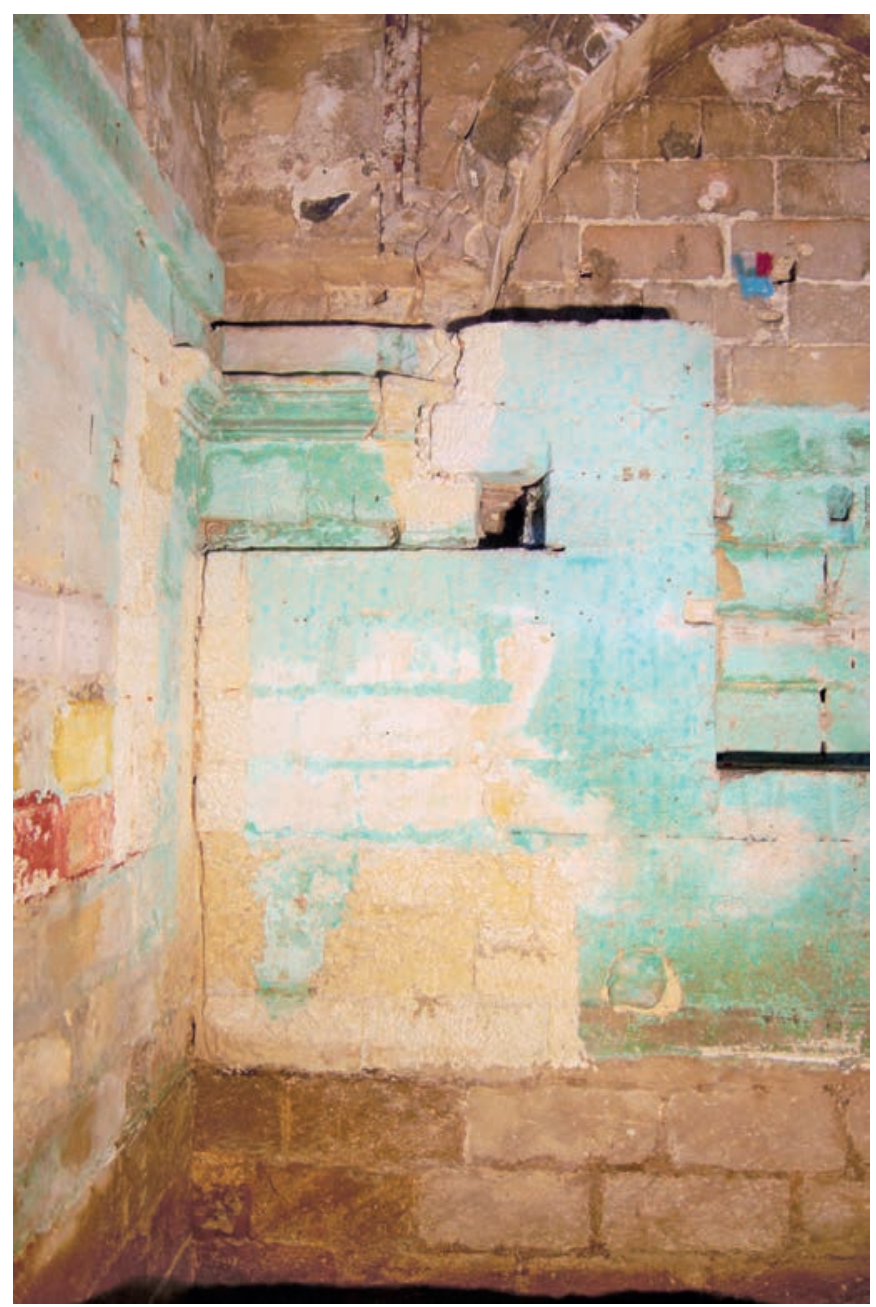

Figura 25. Intervención en el s. XIX en las molduras y el arcosolio del muro 9-A-C.

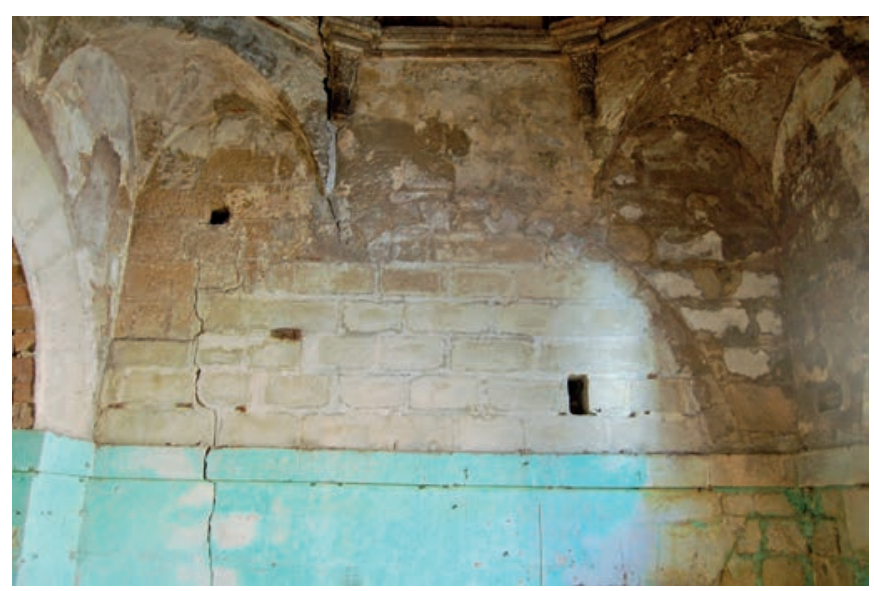

Figura 26. Intervención en el s. XIX. Cegado del arco rehundido en 7-C-A.

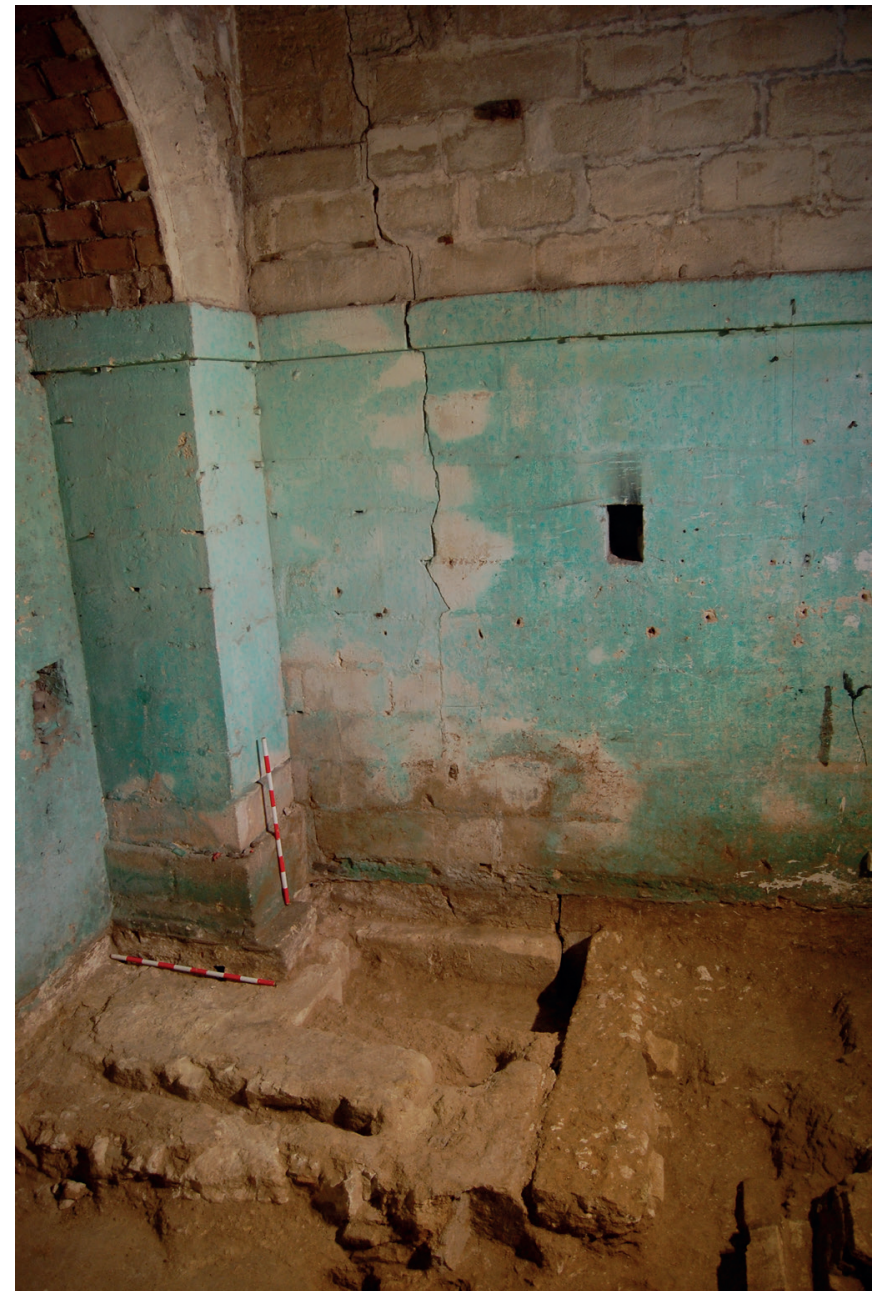

Figura 27. Intervención en el s. XIX sobre el muro C-9-7 y el estribo en 7 -C.

En el paramento contiguo 7-A-C se cegó toda la superficie del arcosolio [UE 141], en el que se abrió un hueco de paso adintelado [UE 5] que, una vez anulada la comunicación de la capilla con la iglesia, permitía el acceso desde la casa rectoral ${ }^{36}$. La reposición de sillares alcanzó una buena parte del estribo de la cabecera incluido en el paramento.

En el muro de fachada, A-7-9, el macizado del arcosolio [UE 158] solo alcanzó la altura de la nueva moldura de piedra, mientras que en el restante, 9-A-C, se aprecia el cajeado en la fábrica original para la moldura de piedra que no se llegó a colocar. El interior del arcosolio decorado con lacería de piedra se cegó parcialmente [UE 23] dejando un hueco en su interior, posiblemente para crear un camarín en el que alojar alguna imagen de culto.

\footnotetext{
${ }^{36}$ Durante las obras de restauración apareció en el dintel de esta puerta una inscripción de grafito de un víctor y el siguiente texto: $A$ D. JOSÉ MORENO.
} 
Los trabajos en el interior de la capilla quedaron interrumpidos. El interior del arcosolio en el muro de la iglesia [UE 13] no se encontraba acabado y presentaba una fábrica de ladrillo y piedra irregular [UE 14]. La moldura incluida en este momento no llegó a colocarse en todo el perímetro, y en algunas zonas se conservaban aún las cuñas de madera utilizadas en su colocación. Además, en los paramentos, habían quedado a la vista numerosos huecos o mechinales [UUEE 31, 32, 132, 135,144 y 172] que fueron ocupados por los apuntalamientos y acodalamientos de la obra. Son de dos tipos, los labrados en el muro original, cuyo cajeado ha mantenido la impronta del cincel, y los resultados de construir la fábrica nueva salvando los codales. Estos huecos se corresponden con las huellas marcadas en la planta de cuatro pies derechos que formarían parte del apuntalamiento interior de la estructura [UUEE 217, $218,219$ y 220$]$.

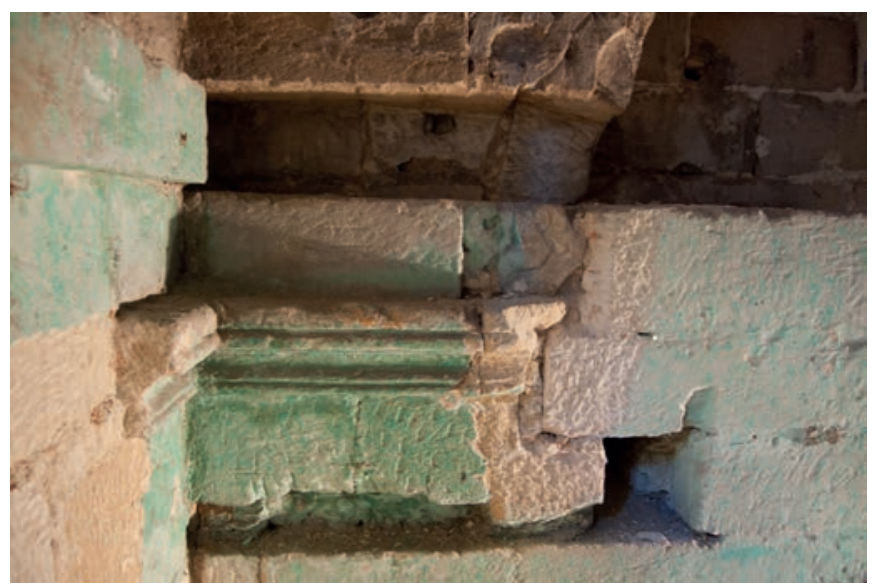

Figura 28. Una de las operaciones del s. XIX inacabadas localizadas en $9-A$.

En este momento se construyó el conjunto bodeguero que se adosa al ábside de la iglesia y a la propia capi1la [UE 9], cuya fachada a la calle San Juan, formada por un muro de mampostería y ladrillo [UE 238], se adosa a los muros de la capilla introduciendo algunas piezas a modo de llave ${ }^{37}$. Por otra parte, aunque no ha podido documentarse, sería lógico pensar que la actuación en la bóveda del ábside de la iglesia estuviera relacionada con la incorporación de los merlones que coronan su perímetro [UUEE 337-340]. Igualmente adscribimos a este momento la actuación en la bóveda de la capilla. En ella parece que se tuvieron que retirar buena parte

\footnotetext{
${ }_{37}$ Según los datos catastrales su fecha de construcción se remonta a 1890.
}

de los rellenos y desmontar el pretil de piedra original sustituyéndolo por otro de ladrillo [UE 249].

En el resto de la iglesia las obras dirigidas por Esteve continuaron con la reparación de la bóveda de terceletes del tramo contiguo al presbiterio, que presentaba señales de ruina. En 1891 ya se habían concluido los trabajos en los espacios de la nave, el coro y la tribuna del órgano estaban arreglados, así como las capillas que abrían hacia la iglesia. Sin embargo, existían otros espacios, como el de la capilla de los Tocino, que había quedado oculta y sin concluir (Álvarez et al. 2003: 108).

En diciembre de 1895, se dieron por finalizadas las obras de restauración del templo, volviendo a abrirse la iglesia, a pesar de que la capilla de los Tocino se encontraba en ese momento:

...cerrada al culto y amenazando ruina por la pesadumbre de la mole de la iglesia, construcción antiquísima del siglo XIII, que se distingue por su elegancia y armónica combinación de nervios de la bóveda, sustentada en fuertes trompa aristadas que la embellecen, existiendo en ella un arco mudéjar de raro mérito por su delicada y original lacería y arrabá ${ }^{38}$.

Esta noticia confirma el efecto que producía sobre esta la fábrica del presbiterio y el primer tramo gótico, su apreciación como elemento de valor singular y su estado de abandono que ha permanecido hasta la reciente restauración.

Los apuntalamientos debieron de ser retirados poco más tarde, para incorporar la capilla a la casa adyacente, que continuaría en uso hasta los años cincuenta del siglo $\mathrm{XX}$, último momento en que sería ocupada por un sacerdote (Repetto 1984: 112-113) ${ }^{39}$. Se conoce que el oratorio sirvió de cocina, realizándose probablemente en este período el cegado de la ventana original [UE 12] y la apertura de una nueva más abajo [UE 10]. A esta etapa deben corresponder también la pintura con decoración de estampados en su interior, la solería hidráulica [UE 194] que se había conservado parcialmente, así como otras huellas menores de mobiliarios de mampostería adosados a los paramentos.

\footnotetext{
38 Muñoz y Gómez A. 1895: "Restauración de San Juan de los Caballeros" El Guadalete. 22 de diciembre, p. 1.

39 La iglesia continuó como sede parroquial solamente hasta 1911, momento en el que tras la reorganización de la diócesis quedó integrada en una nueva entidad denominada de los Cuatro Evangelistas, que incluía otras tantas parroquias intramuros.
} 

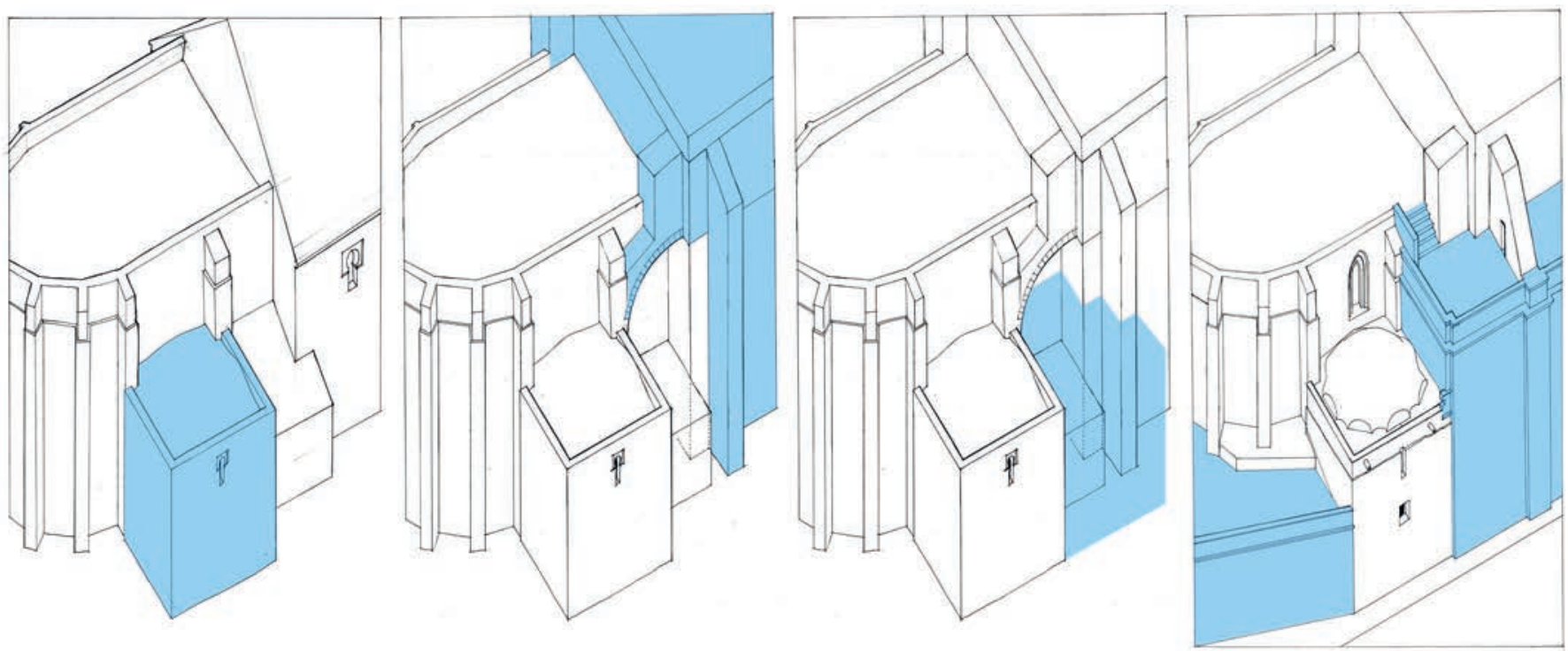

Figura 29. Axonometrías resumen del proceso evolutivo desde la construcción de la capilla hasta la de las casas anexas.

\section{FASE F: Operaciones contemporáneas}

Durante los años 1960 a 1972 en que la iglesia es cedida por el obispado a la Vicaría General Castrense, para prestar servicio como parroquia, la capilla continuó cerrada y olvidada (Repetto 1984: 112-113). En 1966 fueron picados y enfoscados los paramentos exteriores de la casa rectoral por el arquitecto Fernando de la Cuadra $^{40}$, siendo muy probable que se picara en ese momento el revestimiento de la fachada de la capilla. Algo más tarde, en 1973, la Hermandad de la Santa Vera-Cruz se trasladó a la iglesia, que se convertirá a partir de entonces en su sede canónica. La capilla sirvió entonces como almacén y lugar de trabajo para las labores propias de una hermandad (Repetto 1984: 112-113), sin que se realicen trabajos para su recuperación.

En 1974, la hermandad encargó al arquitecto Juan Torreira la eliminación del coro alto, instalado allí en las obras decimonónicas, para recuperar las dimensiones originales de la puerta principal del templo. Este mismo arquitecto dirigiría las obras necesarias para la reapertura del templo tras su cierre en 1981 por la caída de un rayo, sin que haya constancia de ninguna intervención sobre la capilla (Álvarez et al. 2003: 112) ${ }^{41}$.

\footnotetext{
${ }^{40}$ Barroso Becerra, M. 2012: Aproximación a las parroquias fundacionales de Jerez de la Frontera. La torre escalera de la Iglesia de San Juan de los Caballeros: un nudo de complejidad arquitectónica. Trabajo Fin de Máster de Investigación. Master en Arquitectura y Patrimonio Histórico. Trabajo inédito, p. 87.

${ }^{41}$ El templo se volvió a reabrir al culto en el año 1988.
}

Entre los años 2003 y 2006 se abordó la restauración y rehabilitación de la Casa Hermandad de la Santa Vera Cruz, antigua casa rectoral, por los arquitectos A. Martínez González y J. L. Trillo de Leyva ${ }^{42}$. Tampoco en esta ocasión se realizaron trabajos en la capilla, salvo diferentes prospecciones en su interior de las que no se cuenta con mayor información ${ }^{43}$.

Finalmente, entre los años 2010 y 2011 , debido al mal estado de la cubierta y las numerosas filtraciones que se estaban produciendo a causa del vertido de pluviales de las cubiertas del ábside sobre la capi1la, se instalaron conducciones para evitar el vertido directo [UUEE 332-335] y, junto a las del resto del edificio, se limpió y resanó la cubierta de la capilla [UE 236] ${ }^{44}$.

\footnotetext{
${ }^{42}$ A. Martínez González y J. L. Trillo: Proyecto de Rehabilitación de la Casa de Hermandad de la Santa Vera-Cruz. 2003-2006.

${ }^{43}$ Se trata de dos catas en los ángulos E y S, previsiblemente abiertos para comprobar la relación entre la capilla y los contrafuertes de la iglesia. Una zanja transversal que recorre la sala en dirección $\mathrm{S}-\mathrm{N}$, de $0,60 \mathrm{~cm}$ de anchura y otros tantos de profundidad). Con anterioridad a 2006 también se planteó una fosa en el centro de la capilla, de forma irregular tendente al círculo (sobre un metro de diámetro) y profundidad de $0,70 \mathrm{~m}$; y una zanja en el paramento Norte de $0,80 \mathrm{~m}$ de anchura por $0,70 \mathrm{~m}$ de profundidad aproximada. De estas actuaciones no hemos tenido más datos que los que ha generado la excavación, ya que se fueron colmatando de manera rápida con la tierra extraída.

${ }^{44}$ Barroso Becerra, M. 2012: Aproximación a las parroquias fundacionales de Jerez de la Frontera. La torre escalera de la Iglesia de San Juan de los Caballeros: un nudo de complejidad arquitectónica. Trabajo Fin de Máster de Investigación. Master en Arquitectura y Patrimonio Histórico. Trabajo inédito, p. 88.
} 


\subsection{Comprensión constructiva y estructural del estado de la capilla a partir del análisis estratigráfico}

La capilla ha sufrido una serie de transformaciones y deformaciones a lo largo de su historia que son consecuencia de su propia construcción y su relación con las unidades edificatorias descritas en el apartado anterior. Hasta aquí se han descrito las huellas que aparecen de forma sincrónica y se ha intentado reconstruir el proceso diacrónico a través de distintas estrategias y métodos analíticos expuestos. Queda ahora interpretar a partir de estos datos que han sido organizados en periodos, las deformaciones y patologías, sus causas y su estado actual, y cómo condicionaron el proyecto de intervención.

\section{Las cargas del ábside sobre la capilla (origen en la acumulación de las reformas descritas)}

El ábside formaba una caja cerrada y estable, estructurada por los muros poligonales, las paredes laterales estribadas y un frente que abría hacia el buque mediante un hueco menor al que actualmente abre a la nave, por entonces este espacio se cubría con una armadura mudéjar de madera. Este hueco se ensancha y amplia para acomodar la construcción del primer tramo tardogótico en 1504, lo que debió debilitar la unidad constructiva del ábside en los puntos más extremos 6-C y 6-D donde ambas estructuras se yuxtaponen, incrementando la carga hacia los laterales, y por lo tanto, hacia la capilla que tratamos.

La construcción de la capilla de los Tocino en 1404, y posteriormente la de los Carrizosa de mucho mayor tamaño, al otro lado del ábside, volvieron a debilitar la estructura del ábside, pues abrieron arcos o puertas en sus muros, y removieron su cimentación.

La asimetría no es un efecto deseado en este tipo de edificios, pues desestabiliza la unidad constructiva y su lógica de funcionamiento. Este puede ser uno de los motivos de la inestabilidad del ábside hacia el noroeste, que se atajó en el s. XIX mediante una anulación de los arcos de ambas capillas laterales, además del relleno de las criptas de la capilla de los Tocino tras la exhumación de los restos óseos, y la creación de un potente recalce bajo el estribo 7-C como se ha podido documentar en la excavación arqueológica.

\section{Los efectos de la propia construcción de la capilla de los Tocino (origen en el periodo B)}

La capilla tiene como cimiento una fábrica bien trabada de sillares que no son más que la continuidad del aparejo visto de los muros, sin relés interiores. La construcción del muro 9-A-C no afectó sustancialmente al estribo del ábside, pues se adosa de una forma limpia, tanto que se echan en falta un mayor número de trabas entre ambos. La anchura del arcosolio se calculó para que el estribo formase uno de sus lados, injertando en este último solo la cornisa que sirve de imposta al arco apuntado. Al ser el muro más ancho que el estribo, lo trasdosa por la parte exterior (hacia la actual bodega), dándole una mayor trabazón que explica la ausencia de llaves por el interior.

En el muro opuesto, el 7-A-C, observamos sin embargo una importante reducción del ancho del estribo debido a la presencia de arcos murales, que representamos por la intersección de ambos elementos. Estos arcos murales reducen el espesor del muro en unos $40 \mathrm{~cm}$, es decir, casi a la mitad. La estabilidad del estribo 7-C se confía al arco de descarga que mantuvo su funcionamiento hasta que se modificaron las condiciones de carga iniciales, probablemente tras la construcción del primer cuerpo de la nave a principios del s. XVI. Estos arcos murales existen en las tres paredes de la capilla, mientras en el muro del presbiterio A-7-9, existió un arco de apertura al ábside de menor dimensión. Estos arcos hacen de extensión visual de la capilla, y recogen de nuevo la tradición de la

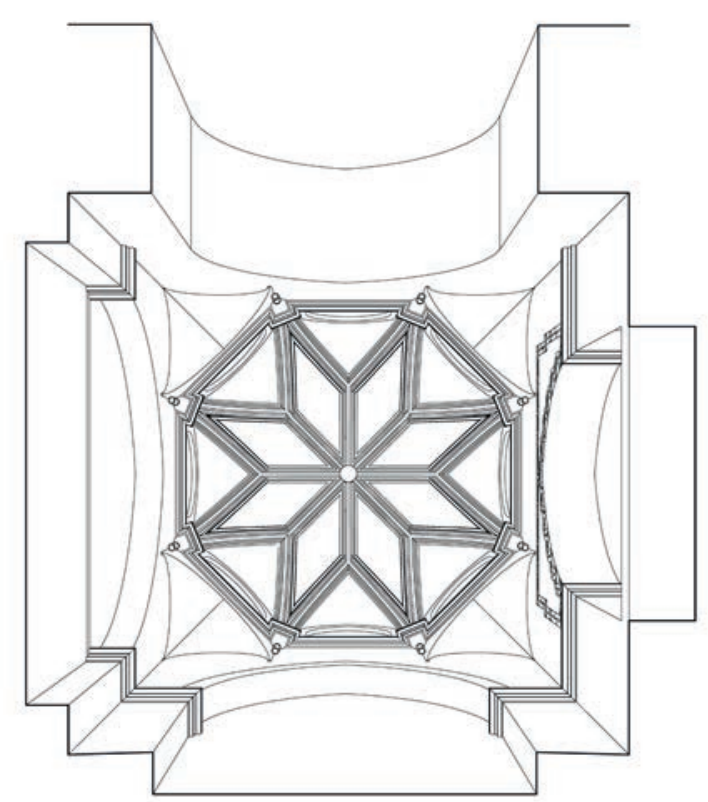

Figura 30. Perspectiva cenital donde se visualizan las reducciones de los muros de la capilla. 
tipología de capilla qubbas funeraria. En esta extensión suelen ubicarse sepulcros escultóricos de bulto redondo que representaban a los donantes. Esta articulación espacial hace que la estructura portante concentre los esfuerzos de las esquinas de la capilla, provocando las grietas que han quedado recogidas en la planimetría.

Dentro de la caja que forman estos muros, confiriéndole una gran unidad estructural, se construye una bóveda ochavada de nervios de piedra que forman una estrella de ocho puntas y plementos de roscas de ladrillo a la soga y canto que se aparejan de forma concéntrica a la clave polar hasta formar aristas sobre los nervios, quedando ocultas por estos últimos. Podríamos decir que la bóveda está formada estructuralmente por varias piezas. Un casquete superior de hiladas concéntricas que se extienden hasta los enjarjes dentro de la forma estrellada, y unas figuras conoides que permiten obtener paños lisos en los paramentos del ochavo terminados en $\operatorname{arcos}$ apuntados $^{45}$. Ambos elementos de ladrillo muestran una gran capacidad autoportante que dependerá de la manera en que estas "partes" queden unidas. Esto ha permitido que la plementería mantenga unida la zona más afectada por los empujes del ábside, produciéndose solo los desplazamientos de nervios sin apenas deformaciones de la fábrica de ladrillo ${ }^{46}$.

Los nervios han actuado girando respecto a la articulación que suponen los enjarjes C-O y C-N. Esta forma de funcionamiento delata que los nervios son piezas independientes desde los capiteles hasta el punto donde se bifurcan. Esta solución podemos considerarla muy primitiva en cuanto a su concepción, pues a lo largo del s. XV evolucionan a soluciones que evitan estos problemas de separación y desgarro, haciendo que las impostas formen un "enjarje", que unifica varios nervios, y las bifurcaciones se construyen también con una sola pieza, generando lo que conocemos como "cruceros" y "claves". Por esta razón todos los nervios afectados han actuado como una pieza solidaria, sin que las dovelas intermedias hayan sufrido desgarros apreciables en los lechos de unión, concentrando las deformaciones en los extremos. Sólo el nervio n-6 (nervio que une la bifurcación con la clave) ofrece estos movimientos en los lechos, resultado del

\footnotetext{
45 Esta técnica del ladrillo aparejado de forma concéntrica ya había dado su resultado en construcciones militares como torres defensivas en la banda morisca cuya caja mural hermética y lisa tiene muchos aspectos comunes con la capilla de los Tocino (Molina 2017).

${ }^{46}$ Así se ha comprobado en los ensayos sobre el comportamiento estructural realizados sobre la bóveda (Compán et al. 2016). Este estudio estructural ha considerado las articulaciones e interfaces desveladas en el análisis constructivo y paramental en la construcción del modelo analítico elaborado.
}
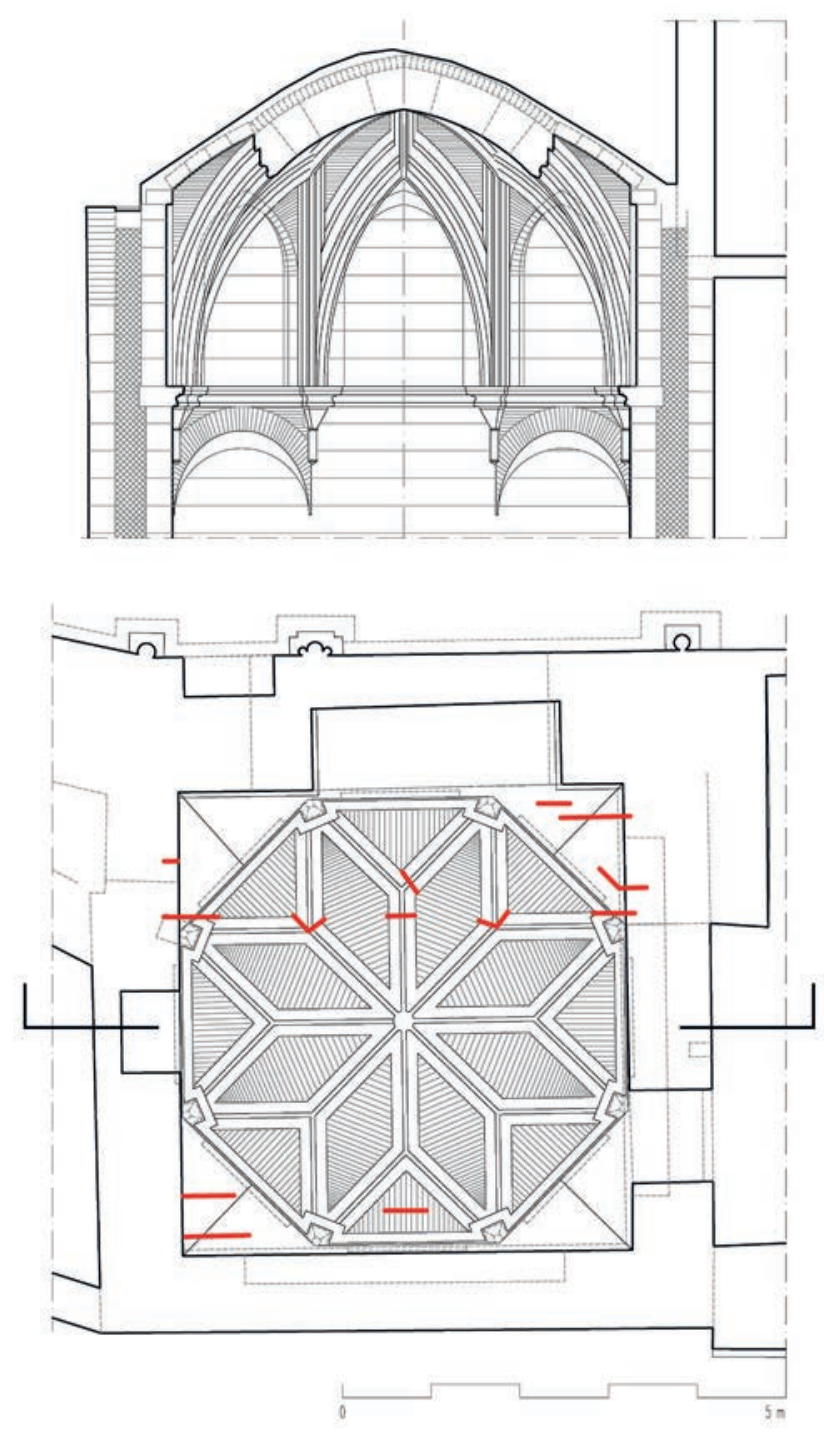

Figura 31. Proyecciones planas donde se visualizan los elementos de la bóveda y se representan las grietas y roturas detectadas en los nervios.

desplazamiento de la línea de carga a la zona superior del nervio. La altura de los nervios es $45 \mathrm{~cm}$, aproximadamente $1 / 11$ de la luz de la capilla, es una sección muy conservadora, sobre todo si consideramos que la sección de la plementería se aproxima a 1/30 de la luz, si contamos el espesor del ladrillo $(14 \mathrm{~cm})$ y el compacto de mortero superior $(2 \mathrm{~cm})$ de cal. Ambas soluciones están superpuestas, ya que no se aprecia en las aperturas inspeccionadas que los nervios tengan un pezón superior que permita la traba. El resto de las piezas de la bóveda se han mantenido unidas y trabadas, funcionando como una gran compacidad. Como ya se indicó en los apartados anteriores, las roturas de los nervios están asociadas a los empujes del presbiterio y la bóveda del primer tramo, estando estabilizadas estas acciones en la actualidad. 


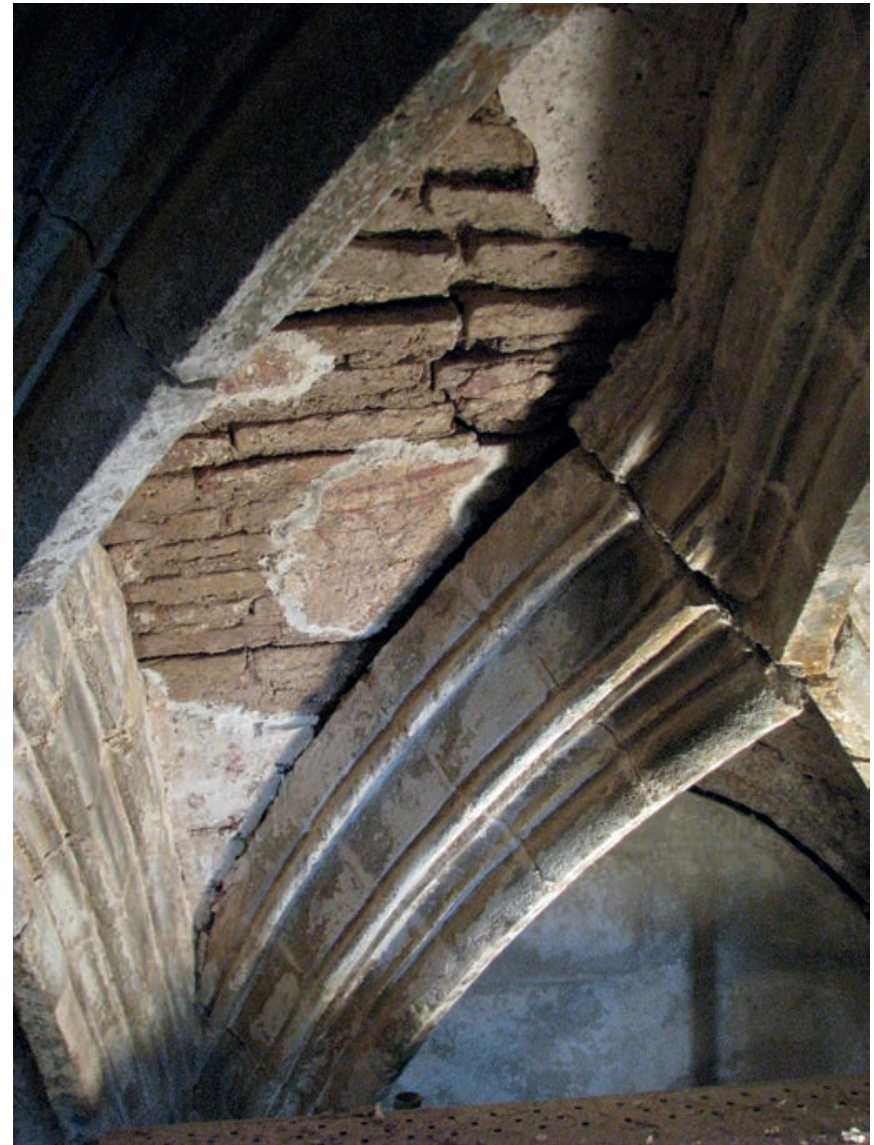

Figura 32. Fotografías del nervio n-7 de la bóveda.

\section{El efecto causado sobre la capilla por las reformas tardogóticas del primer tramo de la nave (origen en el periodo $C$ )}

La consecuencia de la construcción del primer tramo de la nave fue la aparición de unos potentes estribos en los extremos y una gran bóveda de terceletes que empuja sobre ellos, tal como aparecen designados en la lectura estratigráfica. Este enorme aparato constructivo supera en altura y magnitud a los restantes del edificio y obliga a modificar la relación entre ellos. Ya se ha citado la apertura del muro 6-C-D para que fluya el espacio del presbiterio hacia el nuevo tramo y la debilidad que ocasionó en los puntos extremos del ábside. A esto debemos sumar ahora la invasión que suponen los contrafuertes de las esquinas de la nueva bóveda de terceletes sobre las estructuras colindantes. En el caso de la esquina B-6, se producen dos estribos, uno que se adosa al exterior del paramento lateral del ábside entre 6-C y 7-C sorteando el estribo del ábside en ese punto, creando un contacto con el muro 7-A-C de la capilla de los Tocino que le provocará con el tiempo empujes perjudiciales en dirección norte, provocando grietas en las zonas más débiles, es decir, donde aparecen las interfaces entre la fábrica de la capilla y al cuerpo del ábside. El otro estribo, que ocupa el espacio entre 6-A y $6-\mathrm{B}$, condicionando la profundidad de la crujía de la casa parroquial.

\section{Los efectos de las construcciones laterales sobre} la capilla (originadas en el periodo $D$ )

Por último, la construcción de la casa anexa, realizada según los indicios documentales a principios del s. XIX, no hicieron más que agravar la situación. La reforma requirió la reutilización de los muros de la capilla de los Tocino y su lindera, la de los Mirabal. Si además contamos con el pozo situado justo en el punto 6-B, que coincide con la esquina exterior del primer tramo de la nave, podemos verificar la importante cantidad de efectos adversos que se concentran en esta parte de la iglesia, que terminarán por concentrar las cargas en el punto 7-C de la capilla, justo donde está más debilitado el estribo, provocando las enormes grietas que pudimos detectar.

Por último, debemos señalar el origen de la alteración de la fábrica exterior en su zona superior que fue terminada en una pobre fábrica de ladrillo. Al comparar gráficamente el alzado interior y exterior de la capilla, observando que la fábrica de ladrillo coincide con la línea de enjarjes de piedra del interior. Esta operación podría interpretarse como una obra inacabada, como consecuencia de la reforma de la casa parroquial para crear un nuevo remate acorde al resto de la fachada siguiendo las pautas del resto que ha quedado construido. Al quedar inconclusa se rehizo parte de esta fábrica con ladrillos hasta alcanzar la altura de un discreto murete. Al intervenir ahora sobre esta zona del edificio hemos podido comprobar que la fábrica de ladrillo era de una construcción muy pobre y los morteros estaban muy degradados hasta el punto de poder retirarse los ladrillos con las manos sin la menor dificultad, razón por la que se ha vuelto a rehacer por completo. Al desmontar esta fábrica no se detectaron operaciones de refuerzo de la bóveda que por lógica constructiva corresponden a los enjarjes, apareciendo sólo los rellenos que colmatan de forma estratificadas en capas sucesivas de mortero pobre los riñones de la bóveda. 


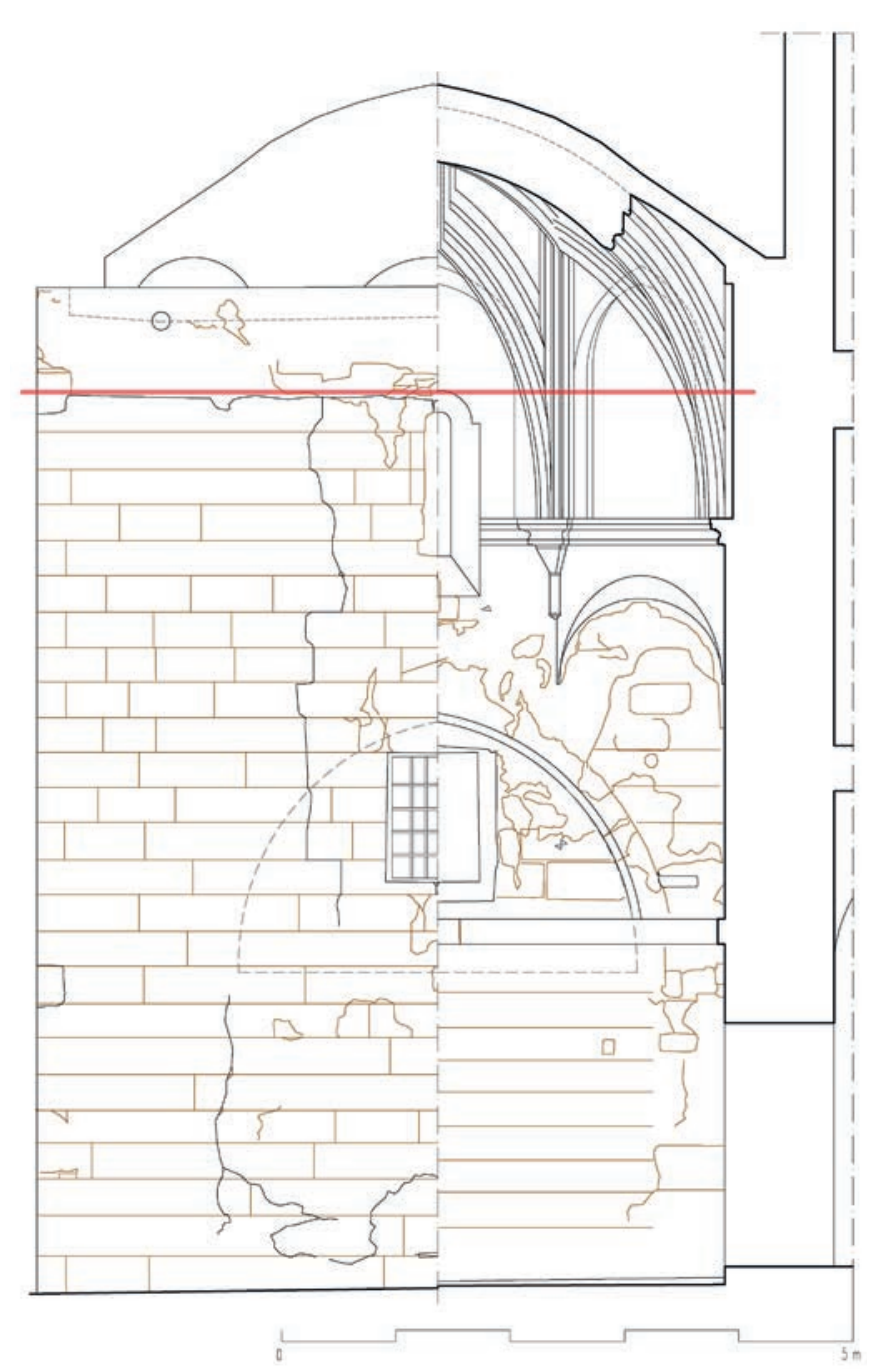

Figura 33. Alzado exterior e interior invertido del muro. Se ha indicado con trazos la proyección del arcosolio interior y la altura de los enjarjes de la bóveda.

\section{Las consecuencias de las reformas de Esteve (originadas en el periodo E)}

La intervención del siglo XIX llevada a cabo por Esteve, intentó atajar como pudo los problemas de inestabilidad descritos, legándonos la solución que hoy observamos, en la que se transformó sustancialmente el subsuelo de la capilla y sus paramentos interiores. La intervención en el presbiterio fue tan potente que dejó sin concluir la capilla de los Tocino en 1895, por falta de presupuesto. Gracias a esta interrupción podemos hoy leer elementos originales de la obra que hubieran desaparecido con su conclusión o por las restauraciones de la primera mitad del s. XX que insistieron en hacer desaparecer revestimientos para dejar a la luz la construcción.
Inicialmente la estabilización estructural del ábside contemplaba la permanencia del hueco de apertura con la capilla de los Tocino, adaptándolo al nuevo diseño decimonónico para el presbiterio siguiendo las normas litúrgicas y estéticas del momento. Esto se deduce del esfuerzo realizado para crear un nuevo arco de medio punto levemente desplazado hacia la esquina 7-C respecto al original. Este desplazamiento pretendía restablecer la estabilidad del muro afectado por numerosas grietas que llegaban hasta el arco antiguo desde el enjarje 8-C y recuperar sitio para llevar hasta el suelo la pilastra asociada a este punto de la bóveda del ábside. Pero en un momento determinado de la intervención, donde se primó el diseño unitario del ábside, se anuló esta apertura, condenando la capilla a un absoluto aislamiento. De este modo, quedó el arco de potentes dovelas de piedra manteniendo incluso en su sitio el encofrado de ladrillo que sobre cimbras de madera ya desaparecidas sirvió para construirlo. Huellas de diversas cimbras, jabalcones, codales y pies derechos de gran dimensión han quedado en las paredes y en los cimientos, tal como se puede observar en la lectura paramental y en la excavación arqueológica.

A tenor de la forma de proceder de Esteve, estos elementos debieron tener una dimensión y configuración bastante potente (Álvarez et al. 2003). La estructura auxiliar levantada en el s. XIX partía de una mejora del terreno que consistió en el vaciado de las tres criptas que ocupaban prácticamente toda la capilla, y su relleno mediante un hormigón de cal y arena compactada de gran dureza que devolvió la capacidad portante al suelo. Una vez estabilizado, se procedió al apuntalamiento de la bóveda y al acodalado de la misma hacia los muros 7-A-C y 9-A-C evitando empujar hacia la fachada. Cuatro grandes postes descargaban la bóveda hacia el suelo, usando como elemento auxiliar estos acodalamientos cuyas huellas han quedado en las paredes. Esta estructura debió permanecer mucho tiempo, pues los refuerzos fueron numerosos.

Como era previsible, el ángulo 7-C recibió una especial atención, pues su fábrica estaría muy afectada por los problemas que se ven descritos en los documentos, rehaciendo por completo la fábrica mediante la sustitución de la hoja de sillares externa. Para ello debió labrarse toda la fábrica, introduciendo la nueva mediante el asiento de los sillares con cuñas de madera que permitían el posterior rellenado de las uniones con un mortero fluido, como era costumbre. Como la capilla estaba totalmente apeada, esta nueva fábrica rodeo a los 
codales. Al desaparecer estos codales han quedado los huecos que ocupaban, lo que nos ha permitido relacionarlos con los que han salido en la excavación.

Los problemas de empujes y movimientos, aunque en menor medida, persistieron hasta la actualidad sin remedio, pues desde entonces quedaron desasistidos al quedar oculta y sin uso la capilla.

\section{Interpretación de las grietas de la fachada}

En cuanto a las grietas observadas en la fachada, dibujan el arco mural interior, sobre todo la inferior que marca la reducción de la fábrica en $40 \mathrm{~cm}$, casi la mitad de su espesor. La grieta superior marcaría el punto de carga del enjarje, donde además se inicia el ochavo del ángulo A-9. Estas grietas son las que se pretendieron arreglar mediante los rellenos interiores antes expuestos, aunque no llegaron a lograrlo por completo, pues en este muro el arco no se cegó por completo.

Podemos concluir que la estructura de la capilla ha recuperado mediante la intervención decimonónica una estabilidad estructural que había perdido a causa de la secuencia de acciones que hemos descrito en apartados anteriores, cuyos efectos negativos son notables y superan en entidad e importancia al diseño original de la capilla. La envergadura del ábside y del primer tramo de la nave son tales, que la capilla seguirá reflejando sus movimientos por muchas intervenciones que se realicen. La estabilidad de las grietas deducibles del seguimiento realizado durante todo un periodo estacional, permite concluir que el edificio ha adquirido una estabilidad adecuada y coherente al proceso constructivo que ha quedado expuesto en apartados anteriores.

\section{La interpretación de las humedades a partir de la lectura de sus fábricas}

Las uniones entre fábricas distintas son puntos habituales de entrada de agua y concentración de humedades si no están bien ejecutadas o han sufrido movimientos. Ambas situaciones se reproducen en el caso que estudiamos, detectando varios puntos críticos. El primero y quizás más evidente es la unión del muro 9 de la capilla con el estribo del presbiterio, que podemos identificar justo con el encuentro del ochavo $\mathrm{N}$, es decir, en el punto 9-N a la altura de la bóveda. Esta unión se produce sin apenas llaves de anclaje como se puede observar en las interfaces expuestas en el estudio paramental. La unión es más débil aún desde la altura de la cornisa hacia el remate del muro 9, tal como se puede observar desde el exterior. Esta unión está ejecutada con fábrica de ladrillo que parece haber sido repuesta en la parte superior, quedando sin retacar. Este es un punto de entrada de agua que coincide con el ochavo $\mathrm{N}$ que en la interior muestra varias grietas en las uniones entre de los nervios y los paramentos verticales. Sobre cada trompa aristada se forma un muro de fábrica que asume la diferencia entre el cuadrado de la planta y el ochavo, y en su interior se rellenó de tierra compactada con cal, que ha recibido y almacenado la entrada de agua que penetra por estas interfaces.

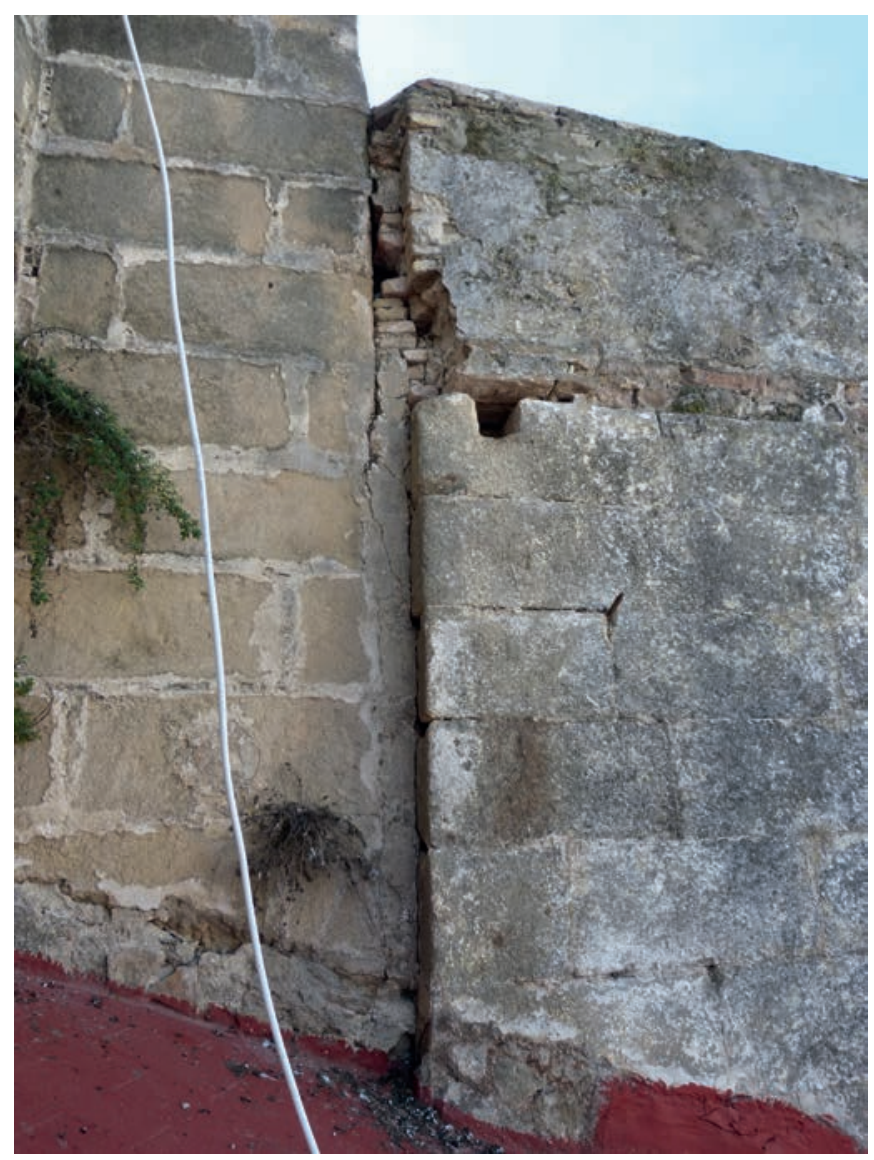

Figura 34. Fotografía de la interfaz en C-9 entre el muro de la capilla y el estribo, desde el exterior.

El último punto de penetración por filtración se produce en la unión con la nave de bodega situada adosada al muro 9-A-C. Este edificio ha estado abandonado y sin uso durante largo tiempo, y sus paramentos exteriores han perdido gran parte de sus revestimientos. Al estar construida esta nave con fábrica de mampuestos y sillares que se traban con la esquina A-9 de la capilla, provocan separaciones y huecos por donde penetra el agua. 
Las humedades de capilaridad o absorción se producen por la ascensión de agua del terreno debido a la porosidad del elemento constructivo, en este caso piedra calcarenita. En el interior, la ascensión de humedad que se percibe claramente en sus paramentos, está distorsionada por la intervención del siglo XIX, donde las fábricas recibieron una importante transformación. Los arcos que existen en sus cuatro muros han sido macizados con fábrica de sillares de piedra trasdosando las fábricas originales. La fábrica nueva, al estar sólo expuesta al interior, ha respondido mejor a la humedad que la antigua. Así se observa en los rincones, donde ha permanecido a la vista la fábrica original, provocando un nivel de humedad en la pared mucho más elevado.

La primera conclusión es que la presencia de humedad es bastante homogénea, apreciándose una mayor altura en el muro A-7-9 al estar expuesto a la intemperie por su cara exterior. También se aprecia un comportamiento distinto de la fábrica original respecto a la construida en el s. XIX. Esta última tiene unos valores de humedad más bajos, aunque no muy distintos pues el material es prácticamente el mismo. En las esquinas de la estancia, donde los sillares originales llegan hasta el suelo, se aprecian variaciones perceptibles que nos dibujan incluso las uniones y los solapes de la fábrica nueva con la antigua. En estos casos hemos obtenido los máximos niveles de humedad. En las zonas excavadas el muro aparece más colmatado de humedad, por el contacto con el terreno de relleno que forma el nivel de uso de la capilla.

\section{CONCLUSIONES}

Todos estos trabajos han confirmado y documentado científicamente que la construcción de la capilla es resultado de un proyecto unitario desde los cimientos hasta la bóveda. La confluencia de los trabajos desarrollados en el proyecto de intervención ha ido apuntalando las hipótesis lanzadas con datos materiales como las huellas, marcas y signos, caracterización de fábricas y elementos formales, contrastados con otros documentales.

Este trabajo ha permitido proponer un referente para programar futuras intervenciones en otros elementos coetáneos que actualmente se encuentran muy deteriorados o transformados en etapas posteriores. La construcción de una metodología que aglutina estudios entendiéndolos como complementarios entre sí -lectura estratigráfica de paramentos, análisis geométricos de control formal, estudio gliptográfico, análisis de revestimientos pictóricos, etc.- - permite un enfoque del problema de conservación que trasciende esta capilla, descubriendo en otras aquellos elementos que en esta se han puesto en valor. Por ejemplo, en el caso de la recuperación y reintegración de las pinturas murales, al ser conocidos los resultados se ha generado una sensibilización respecto a estos elementos en el resto de capillas que aún los conservan de forma testimonial.

En lo que respecta a la intervención arquitectónica sobre la capilla se han intentado conciliar dos objetivos básicos. Por un lado, recuperar su identidad espacial original como testimonio de un momento de especial relevancia en la historia arquitectónica del edificio y del marco jerezano, en el que se reconoce la actuación en unas fechas muy tempranas de un taller de canteros y maestros, de gran influencia en el entorno geográfico, generando un modelo de capilla funeraria que muestra el mestizaje entre elementos formales andalusíes y castellanos. De otra parte, compatibilizar con lo anterior los esfuerzos llevados a cabo por Esteve en el s. XIX para contener la degradación, y posiblemente la pérdida de esta capilla, en los que se reconoce su efectividad. Para ello la adecuada delimitación de las regiones e interfaces obtenidas de la lectura paramental han sido imprescindibles.

Las actuaciones sobre cada una de estas dos realidades se han jerarquizado conforme al valor asignado a cada parte y a la necesidad de recuperar el conjunto, persiguiendo tanto la lectura de los procesos de transformación como la recuperación de ciertos valores, formales y espaciales de la obra original, sin perder el estatus actual de la capilla que sigue aislada del templo. El tratamiento de partes revestidas de nuevo y partes en piedra vista persigue este objetivo, apoyándose para ello en los trabajos y análisis realizados previos y paralelos.

Por último, la difusión de esta metodología es imprescindible para la comprensión de la arquitectura histórica como un objeto complejo, donde la sincronía que observamos no puede interpretarse como resultado de un solo hecho histórico, sino como acumulación, superposición y en muchos casos conflicto de muchos acontecimientos y posicionamientos culturales y sociales distintos. Para ello el parámetro tiempo debe estar precisado por datos que validen las decisiones tomadas en la intervención. 


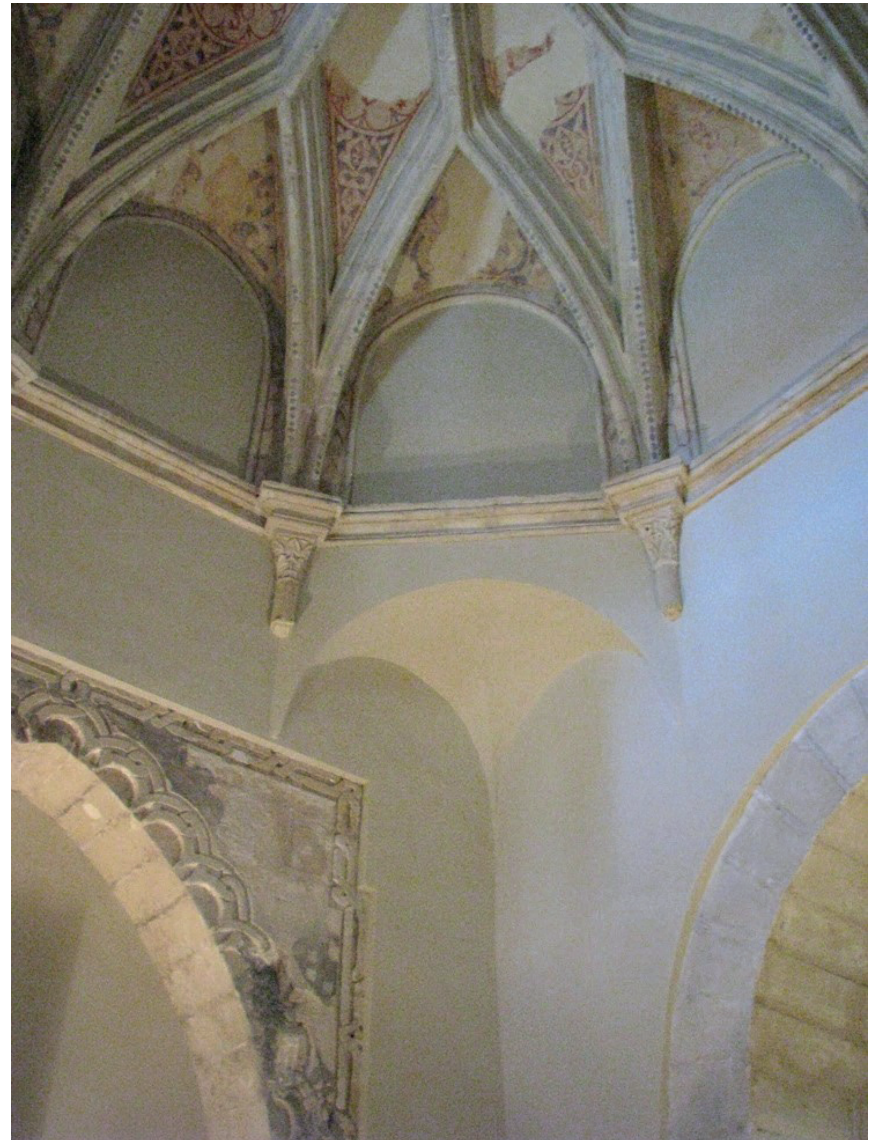

Figura 35. Interior de la capilla restaurada.

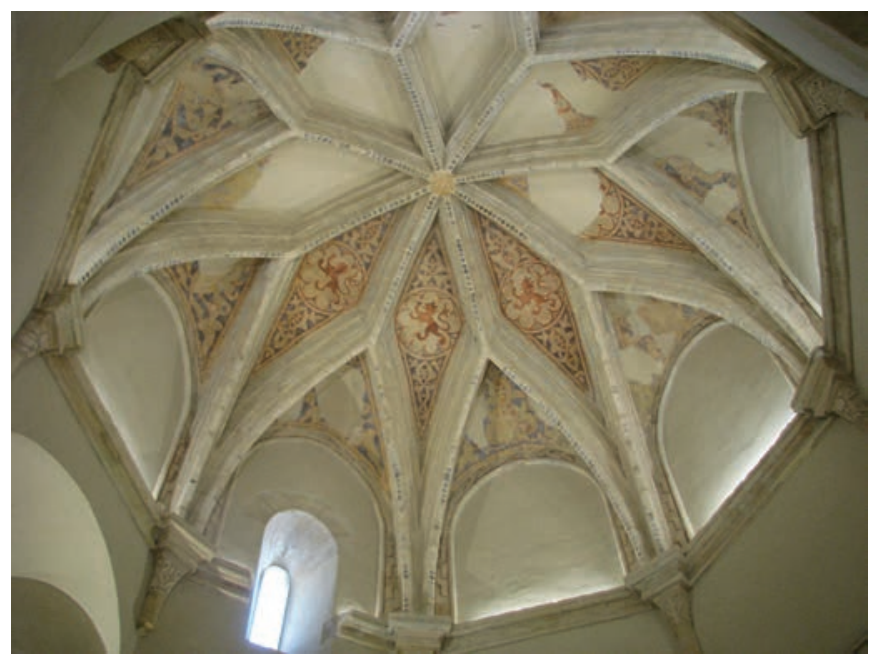

Figura 36. Interior de la capilla restaurada. Bóveda.

Todo esto hubiera sido imposible, o al menos arriesgado, sin el registro, inventario y análisis de la información obtenida durante los trabajos, a partir de todos los enfoques desarrollados. La puesta al día de las hipótesis y conjeturas que existían sobre el edificio, así como el registro de los resultados de esta investigación son parte de su recuperación y puesta en valor.

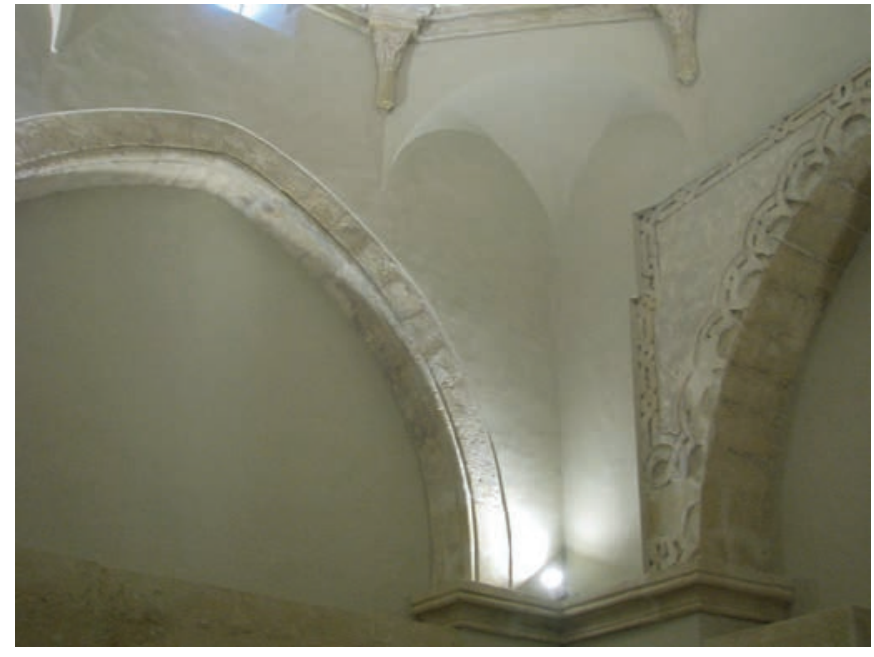

Figura 37. Interior de la capilla restaurada. Arcosolio

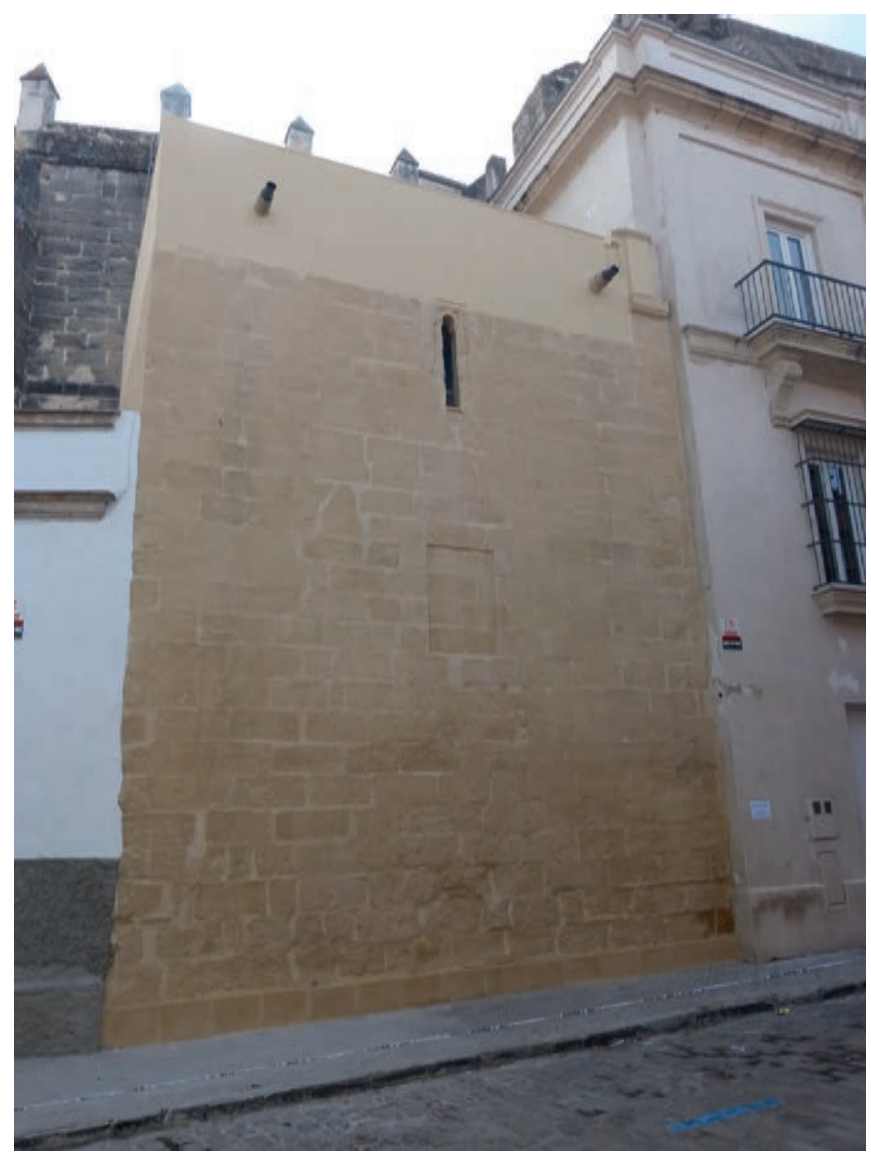

Figura 38. Exterior de la capilla restaurada.

En este proceso, la valoración de las patologías y el estado estructural del edificio ha sido sustancial, y no es posible sin la consideración de su complejidad diacrónica. Como consecuencia, la toma de decisiones se realiza en función de la discusión sobre todo este material, sobre miradas y opiniones cruzadas, quedando en un lugar necesariamente acordado. En este contexto, 
la reversibilidad no está tanto en la facilidad de montaje y desmontaje de las instalaciones o elementos añadidos, sino en la posibilidad de poder reconocer la trazabilidad del proceso, de recuperar información que ahora puede quedar oculta, mediante una información estructurada y localizable. La etapa vital del edificio durante este proceso de intervención debe quedar registrada e integrada como consecuencia del propio proyecto, entendido este como conjunto, no sólo como obra material.

\section{BIBLIOGRAFÍA}

Alonso Ruiz, B. y Martínez de Aguirre, J. 2011: “Arquitectura en la Corona de Castilla en torno a 1412", Artigrama, 26, pp. 103-147.

Álvarez Luna, A., Guerrero Vega, J. M. y Romero Bejarano, M. 2003: La intervención en el Patrimonio. El caso de las iglesias jerezanas (1800-2000). Ayuntamiento de Jerez, Jerez.

Aroca Vicenti, F. 2002: Arquitectura y urbanismo en el Jerez del siglo XVIII. Centro Universitario de Estudios Sociales, Jerez.

Bango Torviso, I. G. 1992: "El espacio para enterramientos privilegiados en la arquitectura medieval española", Anuario del Departamento de Historia y Teoría del Arte, 4, pp. 93-132.

Borrego Soto, M. A. 2016: La revuelta mudéjar y la conquista cristiana de Jerez (1261-1267). Peripecia Libros, Jerez.

Caballero Zoreda, L. 1995: "Método para el análisis estratigráfico de construcciones históricas o "lectura de paramentos"”, Informes de la Construcción, 435, pp. 38-46. https://doi.org/10.3989/ic.1995.v46.i435.1096

Caramazana Malia, D. y Romero Bejarano, M. 2016: "Nuevos datos de la escultura funeraria en Jerez de la Frontera durante la Baja Edad Media. Las laudas flamencas de San Juan de los Caballeros", Estudios sobre Patrimonio, Cultura y Ciencias Medievales, 18, pp. 195-218.

Compán, V.; Pachón, P. y Cámara, M. 2016: "Evaluación de una intervención mediante análisis modal operacional. Capilla de la Jura en la iglesia de San Juan de los Caballeros (Jerez de la Frontera, Cádiz)", en REHABEND 2016. Construction Pathology, Rehabilitation Technology And Heritage Management (6th REHABEND Congress) Burgos (Spain), May 24th -27th, 2016, pp. 1016-1024. Lombillo Vozmediano, Burgos.

Gámiz Gordo A. 2004: "Paisajes urbanos vistos desde globo: dibujos de Guesdon sobre fotos de Clifford hacia 1853-55", Revista de Expresión Gráfica Arquitectónica, 9, pp. 110-117.

González Jiménez, M. y González Gómez, A. 1980: El Libro de Repartimiento de Jerez de la Frontera. Estudio y edición. Diputación Provincial de Cádiz, Cádiz.

Guerrero Vega, J. M. 2009: "La construcción de la torre Atalaya de Jerez de la Frontera”, en Actas del VI Congreso de Historia de la Construcción. Valencia, 21-24 octubre 2009, pp. 701-710. Instituto Juan de Herrera, Madrid.

Guerrero Vega, J. M. 2019: Espacio y construcción en la arquitectura religiosa medieval de Jerez de la Frontera (s. XIII-XV). Editorial Universidad de Sevilla, Sevilla.

Jácome González, J. y Antón Portillo, J. 2007: “La Capilla de la Jura, de San Juan de los Caballeros de Jerez de la Frontera: entre la épica y la realidad histórica", Revista de Historia de Jerez, 13, pp. 183-211.

Jiménez Martín, A y Pinto Puerto, F. 2003: Levantamiento y Análisis de Edificios. Tradición y futuro, colección textos de doctorado, serie arquitectura, $\mathrm{n}^{\circ}$ 30. Universidad de Sevilla, Sevilla.
Latorre González-Moro, P. y Caballero Zoreda, L. 1995: "La importancia del análisis estratigráfico de las construcciones históricas en el debate sobre la restauración monumental”, Informes de la Construcción, 435, pp. 5-18. https://doi.org/10.3989/ic.1995.v46.i435.1093

López Vargas-Machuca, F. 1999: "Espacios funerarios de la aristocracia en la arquitectura medieval jerezana”, Revista de Historia de Jerez, 5, pp. 71-83.

López Vargas-Machuca, F. 2014: "Entre la tradición castellana y la herencia Andalusí. La arquitectura religiosa en Jerez de la Frontera desde la conquista cristiana hasta la irrupción del tardogótico (1264-1464)", en Limes Fidei, 750 años de Cristianismo en Jerez, pp. 65-99. Diócesis de Asidonia-Jerez, Jerez.

Mesa Xinete, F. [1754]1888: Historia sagrada y politica de la muy noble y muy leal ciudad de Tarteso, Turdeto, Asta Regia, Asido cesariana, Asidonia, Gera, Jerez Sidonia, hoy Jerez de la Frontera. Imprenta de Melchor García, Jerez.

Molina Rozalem, J. F. 2017: Fortificaciones de la Banda Morisca en la provincia de Sevilla. Colección Arte Hispalense, $n^{\circ}$ 109. Diputación de Sevilla, Sevilla.

Mora Vicente, G. M. y Guerrero Vega, J. M. 2015: “Traza y proceso constructivo de la capilla de la Jura de Jerez de la Frontera", en Actas del Noveno Congreso Nacional y Primer Congreso Internacional Hispanoamericano de Historia de la Construcción. Segovia, 13-17 de octubre de 2015, 2, pp.1121-1131. Instituto Juan de Herrera, Madrid.

Pachón, P., Compán, V., Cámara, P. M. de la y Pinto Puerto, F. 2016: “Control of structural intervention by using Operational Modal Analysis. San Juan de los Caballeros church (Cádiz, Spain)", en Structural Analysis of Historical Constructions. Anamnesis, diagnosis, therapy, control, pp. 299-312. CRC Press, Londres.

Pinto Puerto, F. y Guerrero Vega, J. M. 2009: “Estudios previos en la capilla de la Antigua en la iglesia de San Miguel, en Morón de la Frontera (Sevilla)", Revista Arqueología de la Arquitetura, 6, pp. 267-286. https://doi. org/10.3989/arqarqt.2009.09011

Pinto Puerto, F. 2013: "Aportaciones al análisis constructivo de fábricas antiguas: La capilla de la Antigua de San Miguel de Morón (1538)", Revista Informes de la Construcción, vol. 65, 530, pp. 163-174. https://doi. org/10.3989/ic. 12.048

Pomar Rodil, P. y Mariscal Rodríguez, M. A. 2001: "Historicismos en las iglesias de Jerez de la Frontera. Los altares-templete", Revista de Historia de Jerez, 7, pp. 83-101.

Pomar Rodil, P. y Mariscal Rodríguez, M. A. 2004: Jerez. Guía artística y monumental. Sílex, Madrid.

Rallón, E. [c1660] 2003: Historia de la ciudad de Xerez de la Frontera y de los reyes que la dominaron desde su primera fundación. Vol. IV. Universidad de Cádiz - Ayuntamiento de Jerez, Jerez.

Repetto Betes, J. L. 1984: La Vera Cruz de Jerez. Fundación Santa MaríaEdiciones SM, Jerez.

Romero, M., Pachón, P., Compán, V., Cámara, M. y Pinto, F. 2018: "Operational Modal Analysis: A Tool for Assessing Changes on Structural Health State of Historical Constructions after Consolidation and Reinforcement Works-Jura Chapel (Jerez de la Frontera, Spain)", Revista Hindawi Shock and Vibration, vol. 2018, https://doi. org/10.1155/2018/3710419

Ruiz Souza, J. C. 2012. "Castilla y la libertad de las artes en el siglo XV. La aceptación de la herencia de Al-Andalus: de la realidad material a los fundamentos teóricos", Anales de Historia del Arte, extra 1, pp. 123-161. https://doi.org/10.5209/rev_anha.2012.39083

Sancho de Sopranis, H. 1934: Introducción al estudio de la arquitectura en Xerez. Guión, Jerez.

Tabales Rodríguez, M. A. 2002: Sistemas de análisis arqueológico en edificios históricos. Universidad de Sevilla, Sevilla.

Torres Balbás, L. 1946: "Menéndez Pidal (Luis). Catedral de Oviedo. Obras de restauración”. Archivo Español de Arte, 74. 